\title{
Statistical Hypothesis Test In Three Factor ANOVA Model Under Fuzzy Environments Using Trapezoidal Fuzzy Numbers
}

\author{
S. Parthiban ${ }^{1, a^{*}}$ and P. Gajivaradhan ${ }^{2, b}$ \\ $1^{1 *}$ Research Scholar, Department of Mathematics, Pachaiyappa's College, \\ Chennai-600 030, Tamil Nadu, India. \\ ${ }^{2}$ Department of Mathematics, Pachaiyappa's College, Chennai-600 030, Tamil Nadu, India. \\ a selvam.parthiban1979@gmail.com, b drgajivaradhan@gmail.com
} Keywords: LSD, Trapezoidal Fuzzy Numbers, Alpha Cut, Membership Function, Ranking
Function, Total Integral Value, Graded Mean Integration Representation.

\begin{abstract}
This paper deals with the problem of three factor ANOVA model (Latin Square DesignLSD) test using Trapezoidal Fuzzy Numbers (tfns.). The proposed test is analysed under various types of trapezoidal fuzzy models such as Alpha Cut Interval, Membership Function, Ranking Function, Total Integral Value and Graded Mean Integration Representation. Finally a comparative view of the conclusions obtained from various test is given. Moreover, two numerical examples having different conclusions have been given for a concrete comparative study.
\end{abstract}

\section{Introduction}

Fuzzy set theory [29] has been applied to many areas which need to manage uncertain and vague data. Such areas include approximate reasoning, decision making, optimization, control and so on. In traditional statistical testing [11], the observations of sample are crisp and a statistical test leads to the binary decision. However, in the real life, the data sometimes cannot be recorded or collected precisely. The statistical hypotheses testing under fuzzy environments has been studied by many authors using the fuzzy set theory concepts introduced by Zadeh [29]. Viertl [23] investigated some methods to construct confidence intervals and statistical tests for fuzzy data. Wu [27] proposed some approaches to construct fuzzy confidence intervals for the unknown fuzzy parameter. A new approach to the problem of testing statistical hypotheses is introduced by Chachi et al. [8]. Mikihiko Konishi et al. [15] proposed a method of ANOVA for the fuzzy interval data by using the concept of fuzzy sets. Hypothesis testing of one factor ANOVA model for fuzzy data was proposed by $\mathrm{Wu}[26,28]$ using the h-level set and the notions of pessimistic degree and optimistic degree by solving optimization problems. Gajivaradhan and Parthiban analysed one-way ANOVA test using alpha cut interval method for trapezoidal fuzzy numbers [16] and they presented a comparative study of 2-factor ANOVA test under fuzzy environments using various methods [17]

Liou and Wang ranked fuzzy numbers with total integral value [14]. Wang et al. presented the method for centroid formulae for a generalized fuzzy number [25]. Iuliana Carmen BĂRBĂCIORU dealt with the statistical hypotheses testing using membership function of fuzzy numbers [12]. Salim Rezvani analysed the ranking functions with trapezoidal fuzzy numbers [20]. Wang arrived some different approach for ranking trapezoidal fuzzy numbers [25]. Thorani et al. approached the ranking function of a trapezoidal fuzzy number with some modifications [21]. Salim Rezvani and Mohammad Molani presented the shape function and Graded Mean Integration Representation for trapezoidal fuzzy numbers [19]. Liou and Wang proposed the Total Integral Value of the trapezoidal fuzzy number with the index of optimism and pessimism [14].

In this paper, we propose a new statistical fuzzy hypothesis testing of ANOVA for three factors of classifications (Latin Square Design-LSD) in which the designated samples are in terms of fuzzy (trapezoidal fuzzy numbers) data. The main idea in the proposed approach is, when we have some vague data about an experiment, what can be the result when the centroid point/ranking grades of those imprecise data are employed in hypothesis testing? For this reason, we use the centroid/ranking grades of trapezoidal fuzzy numbers (tfns.) in hypothesis testing. 
Suppose the observed samples are in terms of tfns., we can evenhandedly use the centroid/ranking grades of tfns. for statistical hypothesis testing. In arriving the centroid/ranking grades of tfns., various methods are used to test which could be the best fit. Therefore, in the proposed approach, the centroid point/ranking grades of tfns. are used in LSD. Moreover we provide the decision rules which are used to accept or reject the fuzzy null and alternative hypotheses. In fact, we would like to counter an argument that the alpha cut interval method can be general enough to deal with 3-factor ANOVA method (LSD) under fuzzy environments. In the decision rules of the proposed testing technique, degrees of optimism, pessimism and h-level sets are not used but they are used in $\mathrm{Wu}[26]$. For better understanding, the proposed fuzzy hypothesis testing technique of LSD using tfns., two different kinds of numerical examples are illustrated at each models. And the same concept can also be used when we have samples in terms of triangular fuzzy numbers $[5,26]$.

\section{Preliminaries}

\section{Definition 2.1. Generalized fuzzy number}

A generalized fuzzy number $\widetilde{A}=(a, b, c, d ; w)$ is described as any fuzzy subset of the real line $\mathbb{R}$, whose membership function $\mu_{\widetilde{\mathrm{A}}}(\mathrm{x})$ satisfies the following conditions:

i. $\quad \mu_{\widetilde{\mathrm{A}}}(\mathrm{x})$ is a continuous mapping from $\mathbb{R}$ to the closed interval $[0, \omega], 0 \leq \omega \leq 1$,

ii. $\mu_{\widetilde{A}}(x)=0$, for all $x \in(-\infty, a]$,

iii. $\mu_{\mathrm{L}}(\mathrm{x})=\mathrm{L}_{\widetilde{\mathrm{A}}}(\mathrm{x})$ is strictly increasing on $[\mathrm{a}, \mathrm{b}]$,

iv. $\mu_{\widetilde{\mathrm{A}}}(\mathrm{x})=\omega$, for all $[\mathrm{b}, \mathrm{c}]$, as $\omega$ is a constant and $0<\omega \leq 1$,

v. $\mu_{\mathrm{R}}(\mathrm{x})=\mathrm{R}_{\widetilde{\mathrm{A}}}(\mathrm{x})$ is strictly decreasing on $[\mathrm{c}, \mathrm{d}]$,

vi. $\mu_{\widetilde{A}}(x)=0$, for all $x \in[d, \infty)$.

where $\mathrm{a}, \mathrm{b}, \mathrm{c}, \mathrm{d}$ are real numbers such that $\mathrm{a}<\mathrm{b} \leq \mathrm{c}<\mathrm{d}$.

Definition 2.2. A fuzzy set $\widetilde{A}$ is called normal fuzzy set if there exists an element (member) ' $x$ ' such that $\mu_{\widetilde{\mathrm{A}}}(\mathrm{x})=1$. A fuzzy set $\widetilde{\mathrm{A}}$ is called convex fuzzy set if $\mu_{\widetilde{\mathrm{A}}}\left(\alpha \mathrm{x}_{1}+(1-\alpha) \mathrm{x}_{2}\right) \geq \min \left\{\mu_{\widetilde{\mathrm{A}}}\left(\mathrm{x}_{1}\right), \mu_{\widetilde{\mathrm{A}}}\left(\mathrm{x}_{2}\right)\right\}$ where $\quad \mathrm{x}_{1}, \mathrm{x}_{2} \in \mathrm{X}$ and $\alpha \in[0,1] . \quad$ The $\quad$ set $\widetilde{\mathrm{A}}_{\alpha}=\left\{\mathrm{x} \in \mathrm{X} / \mu_{\widetilde{\mathrm{A}}}(\mathrm{x}) \geq \alpha\right\}$ is said to be the $\alpha$ - cut of a fuzzy set $\widetilde{\mathrm{A}}$.

Definition 2.3. A fuzzy subset $\widetilde{A}$ of the real line $\mathbb{R}$ with membership function $\mu_{\widetilde{A}}(x)$ such that $\mu_{\widetilde{A}}(x): \mathbb{R} \rightarrow[0,1]$, is called a fuzzy number if $\widetilde{A}$ is normal, $\widetilde{A}$ is fuzzy convex, $\mu_{\widetilde{A}}(x)$ is upper semi-continuous and $\operatorname{Supp}(\widetilde{\mathrm{A}})$ is bounded, where $\operatorname{Supp}(\widetilde{\mathrm{A}})=\operatorname{cl}\left\{\mathrm{x} \in \mathbb{R}: \mu_{\widetilde{\mathrm{A}}}(\mathrm{x})>0\right\}$ and 'cl' is the closure operator.

It is known that for a normalized tfn. $\widetilde{A}=(a, b, c, d ; 1)$, there exists four numbers $a, b, c, d \in \mathbb{R}$ and two functions $\mathrm{L}_{\widetilde{A}}(\mathrm{x}), \mathrm{R}_{\widetilde{\mathrm{A}}}(\mathrm{x}): \mathbb{R} \rightarrow[0,1]$, where $\mathrm{L}_{\widetilde{\mathrm{A}}}(\mathrm{x})$ and $\mathrm{R}_{\widetilde{\mathrm{A}}}(\mathrm{x})$ are non-decreasing and nonincreasing functions respectively. And its membership function is defined as follows:

$\mu_{\widetilde{\mathrm{A}}}(\mathrm{x})=\mathrm{L}_{\widetilde{\mathrm{A}}}(\mathrm{x})=(\mathrm{x}-\mathrm{a}) /(\mathrm{b}-\mathrm{a})$ for $\mathrm{a} \leq \mathrm{x} \leq \mathrm{b} ; 1$ for $\mathrm{b} \leq \mathrm{x} \leq \mathrm{c} ; \mathrm{R}_{\widetilde{\mathrm{A}}}(\mathrm{x})=(\mathrm{x}-\mathrm{d}) /(\mathrm{c}-\mathrm{d})$ for $\mathrm{c} \leq \mathrm{x} \leq \mathrm{d}$ and 0 otherwise. The functions $\mathrm{L}_{\widetilde{\mathrm{A}}}(\mathrm{x})$ and $\mathrm{R}_{\widetilde{\mathrm{A}}}(\mathrm{x})$ are also called the left and right side of the fuzzy 
number $\widetilde{A}$ respectively [9]. In this paper, we assume that $\int_{-\infty}^{\infty} \widetilde{A}(x) d x<+\infty$ and it is known that the $\alpha$-cut of a fuzzy number is $\widetilde{\mathrm{A}}_{\alpha}=\left\{\mathrm{x} \in \mathbb{R} / \mu_{\widetilde{\mathrm{A}}}(\mathrm{x}) \geq \alpha\right\}$, for $\alpha \in(0,1]$ and $\widetilde{\mathrm{A}}_{0}=\mathrm{cl}\left(\bigcup_{\alpha \in(0,1]} \widetilde{\mathrm{A}}_{\alpha}\right)$, according to the definition of a fuzzy number, it is seen at once that every $\alpha$-cut of a fuzzy number is a closed interval. Hence, for a fuzzy number $\widetilde{A}$, we have $\widetilde{A}(\alpha)=\left[\widetilde{A}_{L}(\alpha), \widetilde{A}_{U}(\alpha)\right]$ where $\mathrm{A}_{\mathrm{L}}(\alpha)=\inf \left\{\mathrm{x} \in \mathbb{R}: \mu_{\widetilde{\mathrm{A}}}(\mathrm{x}) \geq \alpha\right\}$ and $\mathrm{A}_{\mathrm{U}}(\alpha)=\sup \left\{\mathrm{x} \in \mathbb{R}: \mu_{\widetilde{\mathrm{A}}}(\mathrm{x}) \geq \alpha\right\}$. The left and right sides of the fuzzy number $\widetilde{A}$ are strictly monotone, obviously, $\widetilde{A}_{L}$ and $\widetilde{A}_{U}$ are inverse functions of $L_{\widetilde{A}}(x)$ and $\mathrm{R}_{\widetilde{A}}(\mathrm{x})$ respectively. Another important type of fuzzy number was introduced in [6] as follows:

Let $a, b, c, d \in \mathbb{R}$ such that $a<b \leq c<d$. A fuzzy number $\widetilde{A}$ defined as $\mu_{\widetilde{A}}(x): \mathbb{R} \rightarrow[0,1]$, $\mu_{\widetilde{A}}(\mathrm{x})=\left(\frac{\mathrm{x}-\mathrm{a}}{\mathrm{b}-\mathrm{a}}\right)^{\mathrm{n}}$ for $\mathrm{a} \leq \mathrm{x} \leq \mathrm{b} ; 1$ for $\mathrm{b} \leq \mathrm{x} \leq \mathrm{c} ;\left(\frac{\mathrm{d}-\mathrm{x}}{\mathrm{d}-\mathrm{c}}\right)^{\mathrm{n}}$ for $\mathrm{c} \leq \mathrm{x} \leq \mathrm{d} ; 0$ otherwise. where $\mathrm{n}>0$, is denoted by $\widetilde{A}=(a, b, c, d)_{n}$. And $L(x)=\left(\frac{x-a}{b-a}\right)^{n}$ and $R(x)=\left(\frac{d-x}{d-c}\right)^{n}$ can also be termed as left and right spread of the tfn. [Dubois and Prade in 1981].

If $\widetilde{A}=(a, b, c, d)_{n}$, then[1-4], $\widetilde{A}_{\alpha}=\left[\widetilde{A}_{L}(\alpha), \widetilde{A}_{U}(\alpha)\right]=[a+(b-a) \sqrt[n]{\alpha}, d-(d-c) \sqrt[n]{\alpha}] ; \alpha \in[0,1]$. When $\mathrm{n}=1$ and $\mathrm{b}=\mathrm{c}$, we get a triangular fuzzy number. The conditions $\mathrm{r}=1, \mathrm{a}=\mathrm{b}$ and $\mathrm{c}=\mathrm{d}$ imply the closed interval and in the case $r=1, a=b=c=d=t$ (some constant), we can get a crisp number ' $t$ '. Since a trapezoidal fuzzy number is completely characterized by $n=1$ and four real numbers $\mathrm{a} \leq \mathrm{b} \leq \mathrm{c} \leq \mathrm{d}$, it is often denoted as $\widetilde{\mathrm{A}}=(\mathrm{a}, \mathrm{b}, \mathrm{c}, \mathrm{d})$. And the family of trapezoidal fuzzy numbers will be denoted by $F^{T}(\mathbb{R})$. Now, for $n=1$ we have a normal trapezoidal fuzzy number $\widetilde{A}=(a, b, c, d)$ and the corresponding $\alpha$ - cut is defined by $\widetilde{\mathrm{A}}_{\alpha}=[\mathrm{a}+\alpha(\mathrm{b}-\mathrm{a}), \mathrm{d}-\alpha(\mathrm{d}-\mathrm{c})] ; \alpha \in[0,1]---(2.4)$. And we need the following results which can be found in [11, 13].

Result 2.1. Let $\mathrm{D}=\{[\mathrm{a}, \mathrm{b}], \mathrm{a} \leq \mathrm{b}$ and $\mathrm{a}, \mathrm{b} \in \mathbb{R}\}$, the set of all closed, bounded intervals on the real line $\mathbb{R}$.

Result 2.2. Let $A=[a, b]$ and $B=[c, d]$ be in $D$. Then $A=B$ if $a=c$ and $b=d$.

\section{Latin Square Design (LSD)}

A Latin square is an arrangement of the letters (varieties) in a square in such a way that each letter occurs once and only once in each row and each column. A Latin square of $\mathrm{n}^{\text {th }}$ order is an arrangement of the symbols or letters in squares such that each symbol occurs once and only once in each row and column. There will be ' $n$ ' rows, ' $n$ ' columns and ' $n$ ' varieties, every symbol appearing ' $n$ ' times in a Latin square. In other words, we consider an agricultural experiment in which $\mathrm{n}^{2}$ plots are taken and arranged in the form of an $\mathrm{n} \times \mathrm{n}$ square such that the plots in each row will be homogeneous as far as possible with respect to one factor of classification, say soil fertility and plots in each column will be homogeneous as far as possible with respect to another factor of classification, say seed quality. Then ' $n$ ' treatments are given to these plots such that each treatment occurs only once in each row and only once in each column. The various possible arrangements obtained in this manner are known as Latin squares of order ' $n$ '. This design of experiment is called the Latin Square Design (LSD). 


\section{ANOVA for three factors of classification}

Let the $\mathrm{N}\left(=\mathrm{n}^{2}\right)$ variate values $\left\{\mathrm{x}_{\mathrm{ij}}\right\}$ representing the yield of paddy, be classified according to three factors. Let the rows, columns and letters stand for the three factors, say soil fertility, seed quality and treatment respectively. We wish to test the null hypothesis that the rows, columns and letters are homogenous viz., there is no difference in the yield of paddy between the rows (due to soil fertility), between the columns (due to seed quality) and between the letters (due to treatments). Let $\mathrm{x}_{\mathrm{ij}}$ be the variate value corresponding to the $\mathrm{i}^{\text {th }}$ row, $\mathrm{j}^{\text {th }}$ column and $\mathrm{k}^{\text {th }}$ letter. Let $\overline{\mathrm{x}}=\frac{1}{\mathrm{n}^{2}} \sum \sum \mathrm{x}_{\mathrm{ij}}, \overline{\mathrm{x}}_{\mathrm{i} *}=\frac{1}{\mathrm{n}} \sum_{\mathrm{j}} \mathrm{x}_{\mathrm{ij}}, \overline{\mathrm{x}}_{* \mathrm{j}}=\frac{1}{\mathrm{n}} \sum_{\mathrm{i}} \mathrm{x}_{\mathrm{ij}}$ and $\overline{\mathrm{x}}_{\mathrm{k}}$ be the mean of the values of $\mathrm{x}_{\mathrm{ij}}$ corresponding to the $\mathrm{k}^{\text {th }}$ treatment. Now, $\mathrm{x}_{\mathrm{ij}}-\overline{\mathrm{x}}=\left(\overline{\mathrm{x}}_{\mathrm{i} *}-\overline{\mathrm{x}}\right)+\left(\overline{\mathrm{x}}_{* \mathrm{j}}-\overline{\mathrm{x}}\right)+\left(\overline{\mathrm{x}}_{\mathrm{k}}-\overline{\mathrm{x}}\right)+\left(\mathrm{x}_{\mathrm{ij}}-\overline{\mathrm{x}}_{\mathrm{i} *}-\overline{\mathrm{x}}_{* \mathrm{j}}-\overline{\mathrm{x}}_{\mathrm{k}}+2 \overline{\mathrm{x}}\right) . \quad$ Therefore,

$\sum \sum\left(\mathrm{x}_{\mathrm{ij}}-\overline{\mathrm{x}}\right)^{2}=\mathrm{n} \sum_{\mathrm{i}}\left(\overline{\mathrm{x}}_{\mathrm{i} *}-\overline{\mathrm{x}}\right)^{2}+\mathrm{n} \sum_{\mathrm{j}}\left(\overline{\mathrm{x}}_{* \mathrm{j}}-\overline{\mathrm{x}}\right)^{2}+\mathrm{n} \sum_{\mathrm{k}}\left(\overline{\mathrm{x}}_{\mathrm{k}}-\overline{\mathrm{x}}\right)^{2}+\sum_{\mathrm{i}} \sum_{\mathrm{j}}\left(\mathrm{x}_{\mathrm{ij}}-\overline{\mathrm{x}}_{\mathrm{i} *}-\overline{\mathrm{x}}_{* \mathrm{j}}-\overline{\mathrm{x}}_{\mathrm{k}}+2 \overline{\mathrm{x}}\right)^{2}$

By expanding this calculation, all the product terms vanish $[16,17]$, so we have $\mathrm{Q}=\mathrm{Q}_{1}+\mathrm{Q}_{2}+\mathrm{Q}_{3}+\mathrm{Q}_{4}$. Also, we can prove that $\mathrm{Q}_{1} /(\mathrm{n}-1), \mathrm{Q}_{2} /(\mathrm{n}-1), \mathrm{Q}_{3} /(\mathrm{n}-1), \mathrm{Q}_{4} /(\mathrm{n}-1)(\mathrm{n}-2)$ and $\mathrm{Q} /\left(\mathrm{n}^{2}-1\right)$ are unbiased estimates of the population variance $\sigma^{2}$ with degrees of freedom $(n-1),(n-1)$, $(n-1),(n-1)(n-2)$ and $\left(n^{2}-1\right)$ respectively. If the sample population is assumed to be normal, all these estimates are independent. Therefore, each of $\left[Q_{1} /(n-1)\right] /\left[Q_{4} /(n-1)(n-2)\right]$, $\left[\mathrm{Q}_{2} /(\mathrm{n}-1)\right] /\left[\mathrm{Q}_{4} /(\mathrm{n}-1)(\mathrm{n}-2)\right]$ and $\left[\mathrm{Q}_{3} /(\mathrm{n}-1)\right] /\left[\mathrm{Q}_{4} /(\mathrm{n}-1)(\mathrm{n}-2)\right]$ follows a F-distribution with $((n-1),(n-1)(n-2))$ degrees of freedom. Then the F-tests are applied and the significance of difference between rows, columns and treatments is analysed. And the descriptions of $\mathrm{Q}, \mathrm{Q}_{1}, \mathrm{Q}_{2}, \mathrm{Q}_{3}$ and $\mathrm{Q}_{4}$ are given below.

$\mathrm{Q}=\sum \sum \mathrm{x}_{\mathrm{ij}}^{2}-\left(\mathrm{T}^{2} / \mathrm{n}^{2}\right)$ where $\mathrm{T}=\sum \sum \mathrm{x}_{\mathrm{ij}} ; \mathrm{Q}_{1}=(1 / \mathrm{n}) \sum \mathrm{T}_{\mathrm{i}}^{2}-\left(\mathrm{T}^{2} / \mathrm{n}^{2}\right)$ where $\mathrm{T}_{\mathrm{i}}=\sum_{\mathrm{j}=1}^{\mathrm{n}} \mathrm{x}_{\mathrm{ij}}$;

$\mathrm{Q}_{2}=(1 / \mathrm{n}) \sum \mathrm{T}_{\mathrm{j}}^{2}-\left(\mathrm{T}^{2} / \mathrm{n}^{2}\right)$ where $\mathrm{T}_{\mathrm{j}}=\sum_{\mathrm{i}=1}^{\mathrm{n}} \mathrm{x}_{\mathrm{ij}} ; \mathrm{Q}_{3}=(1 / \mathrm{n}) \sum \mathrm{T}_{\mathrm{k}}^{2}-\left(\mathrm{T}^{2} / \mathrm{n}^{2}\right)$ where $\mathrm{T}_{\mathrm{k}}$ is the sum of all $\mathrm{x}_{\mathrm{ij}}$ 's receiving the $\mathrm{k}^{\text {th }}$ treatment and $\mathrm{Q}_{4}=\mathrm{Q}-\left(\mathrm{Q}_{1}+\mathrm{Q}_{2}+\mathrm{Q}_{3}\right)$. Also, $\mathrm{T}=\sum_{\mathrm{i}} \mathrm{T}_{\mathrm{i}}=\sum_{\mathrm{j}} \mathrm{T}_{\mathrm{j}}=\sum_{\mathrm{k}} \mathrm{T}_{\mathrm{k}}$.

The ANOVA table for three factors of classification

\begin{tabular}{|l|c|c|c|c|}
\hline $\begin{array}{l}\text { Source of } \\
\text { Variation (S.V.) }\end{array}$ & $\begin{array}{l}\text { Sum of Squares } \\
\text { (S.S.) }\end{array}$ & $\begin{array}{l}\text { Degree of } \\
\text { Freedom (d.f.) }\end{array}$ & $\begin{array}{l}\text { Mean Square } \\
\text { (M.S.) }\end{array}$ & $\begin{array}{l}\text { Variance Ratio } \\
\text { (F) }\end{array}$ \\
\hline Between Rows & $\mathrm{Q}_{1}$ & $(\mathrm{n}-1)$ & $\mathrm{M}_{1}=\mathrm{Q}_{1} /(\mathrm{n}-1)$ & $\mathrm{F}_{\mathrm{R}}=\left(\frac{\mathrm{M}_{1}}{\mathrm{M}_{4}}\right)^{ \pm 1}$ \\
\hline $\begin{array}{l}\text { Between } \\
\text { Columns }\end{array}$ & $\mathrm{Q}_{2}$ & $(\mathrm{n}-1)$ & $\mathrm{M}_{2}=\mathrm{Q}_{2} /(\mathrm{n}-1)$ & $\mathrm{F}_{\mathrm{C}}=\left(\frac{\mathrm{M}_{2}}{\mathrm{M}_{4}}\right)^{ \pm 1}$ \\
\hline $\begin{array}{l}\text { Between } \\
\text { Treatments }\end{array}$ & $\mathrm{Q}_{3}$ & $(\mathrm{n}-1)$ & $\mathrm{M}_{3}=\mathrm{Q}_{3} /(\mathrm{n}-1)$ & $\mathrm{F}_{\mathrm{T}}=\left(\frac{\mathrm{M}_{3}}{\mathrm{M}_{4}}\right)^{ \pm 1}$ \\
\hline Residual & $\mathrm{Q}_{4}$ & $(\mathrm{n}-1)(\mathrm{n}-2)$ & $\mathrm{M}_{4}=\mathrm{Q}_{4} /(\mathrm{n}-1)(\mathrm{n}-2)$ & - \\
\hline Total & $\mathrm{Q}^{\left(\mathrm{n}^{2}-1\right)}$ & -- & - \\
\hline
\end{tabular}

Latin square is useful when one wishes to remove from an analysis of data the effect of a factor which we are not interested in, but which is known to be significant. Latin square designs are used in industrial, laboratory field, green house, educational, medical, marketing and sociological 
experimentation in addition to agricultural problems. Some advantages of the LSD over other designs are (i) it controls more of the variation than the completely randomized block design [16] with a two way stratification (ii) The analysis is simple (iii) Even with missing data, the analysis remains relatively simple. The assumption made in LSD model is that the interactions between treatments, row and column groupings are non-existent.

\section{Three-factor ANOVA test with tfns. using alpha cut interval method}

The fuzzy test of hypotheses of three-factor ANOVA model where the sample data are trapezoidal fuzzy numbers is given here. Using the relation, we transform the fuzzy ANOVA model to interval ANOVA model. Having the upper limit of the fuzzy interval, we construct upper level crisp ANOVA model and using the lower limit of the fuzzy interval, we construct the lower level crisp ANOVA model. Thus, in this approach, two crisp ANOVA models are designated in terms of upper and lower levels. Finally, we analyse the lower and upper level models using crisp two-factor ANOVA technique. For lower level model, from $\alpha$-cut intervals of tfns. we have, $\mathrm{a}_{\mathrm{ij}}+\alpha\left(\mathrm{b}_{\mathrm{ij}}-\mathrm{a}_{\mathrm{ij}}\right)$ where $0 \leq \mathrm{i} \leq \mathrm{n} ; 0 \leq \mathrm{j} \leq \mathrm{n}$ and for upper level model, $\mathrm{d}_{\mathrm{ij}}-\alpha\left(\mathrm{d}_{\mathrm{ij}}-\mathrm{c}_{\mathrm{ij}}\right)$ where $0 \leq \mathrm{i} \leq \mathrm{n} ; 0 \leq \mathrm{j} \leq \mathrm{n}$. The required formulae are given below:

For lower level model: $x_{i j}=\left[a_{i j}+\alpha\left(b_{i j}-a_{i j}\right)\right] ; \quad \sum \sum x_{i j}^{2}=\sum \sum\left[a_{i j}+\alpha\left(b_{i j}-a_{i j}\right)\right]^{2}$; $\mathrm{T}=\sum \sum \mathrm{x}_{\mathrm{ij}}=\sum \sum\left[\mathrm{a}_{\mathrm{ij}}+\alpha\left(\mathrm{b}_{\mathrm{ij}}-\mathrm{a}_{\mathrm{ij}}\right)\right] ; \mathrm{T}_{\mathrm{i}}=\sum_{\mathrm{j}=1}^{\mathrm{n}}\left[\mathrm{a}_{\mathrm{ij}}+\alpha\left(\mathrm{b}_{\mathrm{ij}}-\mathrm{a}_{\mathrm{ij}}\right)\right] ; \mathrm{T}_{\mathrm{j}}=\sum_{\mathrm{i}=1}^{\mathrm{n}}\left[\mathrm{a}_{\mathrm{ij}}+\alpha\left(\mathrm{b}_{\mathrm{ij}}-\mathrm{a}_{\mathrm{ij}}\right)\right] ; \mathrm{T}_{\mathrm{k}}=$ the sum of all $\left[\mathrm{a}_{\mathrm{ij}}+\alpha\left(\mathrm{b}_{\mathrm{ij}}-\mathrm{a}_{\mathrm{ij}}\right)\right] \quad$ receiving the $\mathrm{k}^{\text {th }}$ treatment, $\mathrm{T}=\sum_{\mathrm{i}} \mathrm{T}_{\mathrm{i}}=\sum_{\mathrm{j}} \mathrm{T}_{\mathrm{j}}=\sum_{\mathrm{k}} \mathrm{T}_{\mathrm{k}} . \quad$ And $\mathrm{Q}^{\mathrm{L}}=\sum \sum \mathrm{x}_{\mathrm{ij}}^{2}-\left(\mathrm{T}^{2} / \mathrm{n}^{2}\right) ; \quad \mathrm{Q}_{1}^{\mathrm{L}}=(1 / \mathrm{n}) \sum \mathrm{T}_{\mathrm{i}}^{2}-\left(\mathrm{T}^{2} / \mathrm{n}^{2}\right) ; \quad \mathrm{Q}_{2}^{\mathrm{L}}=(1 / \mathrm{n}) \sum \mathrm{T}_{\mathrm{j}}^{2}-\left(\mathrm{T}^{2} / \mathrm{n}^{2}\right) ;$ $\mathrm{Q}_{3}^{\mathrm{L}}=(1 / \mathrm{n}) \sum \mathrm{T}_{\mathrm{k}}^{2}-\left(\mathrm{T}^{2} / \mathrm{n}^{2}\right)$ and $\mathrm{Q}_{4}^{\mathrm{L}}=\mathrm{Q}^{\mathrm{L}}-\left(\mathrm{Q}_{1}^{\mathrm{L}}+\mathrm{Q}_{2}^{\mathrm{L}}+\mathrm{Q}_{3}^{\mathrm{L}}\right) \forall \alpha, \alpha \in[0,1]$.

For upper level model: $\mathrm{x}_{\mathrm{ij}}=\left[\mathrm{d}_{\mathrm{ij}}-\alpha\left(\mathrm{d}_{\mathrm{ij}}-\mathrm{c}_{\mathrm{ij}}\right)\right] ; \quad \sum \sum \mathrm{x}_{\mathrm{ij}}^{2}=\sum \sum\left[\mathrm{d}_{\mathrm{ij}}-\alpha\left(\mathrm{d}_{\mathrm{ij}}-\mathrm{c}_{\mathrm{ij}}\right)\right]^{2}$; $\mathrm{T}=\sum \sum \mathrm{x}_{\mathrm{ij}}=\sum \sum\left[\mathrm{d}_{\mathrm{ij}}-\alpha\left(\mathrm{d}_{\mathrm{ij}}-\mathrm{c}_{\mathrm{ij}}\right)\right] ; \mathrm{T}_{\mathrm{i}}=\sum_{\mathrm{j}=1}^{\mathrm{n}}\left[\mathrm{d}_{\mathrm{ij}}-\alpha\left(\mathrm{d}_{\mathrm{ij}}-\mathrm{c}_{\mathrm{ij}}\right)\right] ; \mathrm{T}_{\mathrm{j}}=\sum_{\mathrm{i}=1}^{\mathrm{n}}\left[\mathrm{d}_{\mathrm{ij}}-\alpha\left(\mathrm{d}_{\mathrm{ij}}-\mathrm{c}_{\mathrm{ij}}\right)\right] ; \mathrm{T}_{\mathrm{k}}=$ the sum of all $\left[\mathrm{d}_{\mathrm{ij}}-\alpha\left(\mathrm{d}_{\mathrm{ij}}-\mathrm{c}_{\mathrm{ij}}\right)\right]$ receiving the $\mathrm{k}^{\text {th }}$ treatment, $\mathrm{T}=\sum_{\mathrm{i}} \mathrm{T}_{\mathrm{i}}=\sum_{\mathrm{j}} \mathrm{T}_{\mathrm{j}}=\sum_{\mathrm{k}} \mathrm{T}_{\mathrm{k}} \cdot \quad$ Similarly, $\mathrm{Q}^{\mathrm{U}}=\sum \sum \mathrm{x}_{\mathrm{ij}}^{2}-\left(\mathrm{T}^{2} / \mathrm{n}^{2}\right) ; \quad \mathrm{Q}_{1}^{\mathrm{U}}=(1 / \mathrm{n}) \sum \mathrm{T}_{\mathrm{i}}^{2}-\left(\mathrm{T}^{2} / \mathrm{n}^{2}\right) ; \quad \mathrm{Q}_{2}^{\mathrm{U}}=(1 / \mathrm{n}) \sum \mathrm{T}_{\mathrm{j}}^{2}-\left(\mathrm{T}^{2} / \mathrm{n}^{2}\right) ;$ $\mathrm{Q}_{3}^{\mathrm{U}}=(1 / \mathrm{n}) \sum \mathrm{T}_{\mathrm{k}}^{2}-\left(\mathrm{T}^{2} / \mathrm{n}^{2}\right)$ and $\mathrm{Q}_{4}^{\mathrm{U}}=\mathrm{Q}^{\mathrm{U}}-\left(\mathrm{Q}_{1}^{\mathrm{U}}+\mathrm{Q}_{2}^{\mathrm{U}}+\mathrm{Q}_{3}^{\mathrm{U}}\right) \forall \alpha, \alpha \in[0,1]$.

The null hypothesis $\widetilde{\mathrm{H}}_{0}: \tilde{\mu}_{1}=\tilde{\mu}_{2}=\cdots=\tilde{\mu}_{\mathrm{n}}$ against the alternative hypothesis $\widetilde{\mathrm{H}}_{\mathrm{A}}: \tilde{\mu}_{1} \neq \tilde{\mu}_{2} \neq \cdots \neq \tilde{\mu}_{\mathrm{n}}$. $\Rightarrow\left[\widetilde{\mathrm{H}}_{0}\right]:\left[\tilde{\mu}_{1}\right]=\left[\tilde{\mu}_{2}\right]=\cdots=\left[\tilde{\mu}_{\mathrm{n}}\right]$ against $\left[\tilde{\mathrm{H}}_{\mathrm{A}}\right]:\left[\tilde{\mu}_{1}\right] \neq\left[\tilde{\mu}_{2}\right] \neq \cdots \neq\left[\tilde{\mu}_{\mathrm{n}}\right]$.

$\Rightarrow\left[\mathrm{H}_{0}^{\mathrm{L}}, \mathrm{H}_{0}^{\mathrm{U}}\right]:\left[\mu_{1}^{\mathrm{L}}, \mu_{1}^{\mathrm{U}}\right]=\left[\mu_{2}^{\mathrm{L}}, \mu_{2}^{\mathrm{U}}\right]=\cdots=\left[\mu_{\mathrm{t}}^{\mathrm{L}}, \mu_{\mathrm{n}}^{\mathrm{U}}\right]$ against $\left[\mathrm{H}_{\mathrm{A}}^{\mathrm{L}}, \mathrm{H}_{\mathrm{A}}^{\mathrm{U}}\right]:\left[\mu_{1}^{\mathrm{L}}, \mu_{1}^{\mathrm{U}}\right] \neq\left[\mu_{2}^{\mathrm{L}}, \mu_{2}^{\mathrm{U}}\right] \neq \cdots \neq\left[\mu_{\mathrm{t}}^{\mathrm{L}}, \mu_{\mathrm{n}}^{\mathrm{U}}\right]$

\section{Between rows:}

The null hypothesis for lower level model: $\mathrm{H}_{0}^{\mathrm{L}}: \mu_{1}^{\mathrm{L}}=\mu_{1}^{\mathrm{L}}=\cdots=\mu_{\mathrm{n}}^{\mathrm{L}}$ against the alternative hypothesis $\mathrm{H}_{\mathrm{A}}^{\mathrm{L}}: \mu_{1}^{\mathrm{L}} \neq \mu_{1}^{\mathrm{L}} \neq \cdots \neq \mu_{\mathrm{n}}^{\mathrm{L}}$.

The null hypothesis for upper level model: $\mathrm{H}_{0}^{\mathrm{U}}: \mu_{1}^{\mathrm{U}}=\mu_{1}^{\mathrm{U}}=\cdots=\mu_{\mathrm{n}}^{\mathrm{U}}$ against the alternative hypothesis $\mathrm{H}_{\mathrm{A}}^{\mathrm{U}}: \mu_{1}^{\mathrm{U}} \neq \mu_{1}^{\mathrm{U}} \neq \cdots \neq \mu_{\mathrm{n}}^{\mathrm{U}}$.

\section{Between columns:}

The null hypothesis for lower level model: $\mathrm{H}_{0}^{\mathrm{L}}: \mu_{1}^{\mathrm{L}}=\mu_{1}^{\mathrm{L}}=\cdots=\mu_{\mathrm{n}}^{\mathrm{L}}$ against the alternative hypothesis $\mathrm{H}_{\mathrm{A}}^{\mathrm{L}}: \mu_{1}^{\mathrm{L}} \neq \mu_{1}^{\mathrm{L}} \neq \cdots \neq \mu_{\mathrm{n}}^{\mathrm{L}}$. 
The null hypothesis for upper level model:

$\mathrm{H}_{0}^{\mathrm{U}}: \mu_{1}^{\mathrm{U}}=\mu_{1}^{\mathrm{U}}=\cdots=\mu_{\mathrm{n}}^{\mathrm{U}}$ against the alternative hypothesis $\mathrm{H}_{\mathrm{A}}^{\mathrm{U}}: \mu_{1}^{\mathrm{U}} \neq \mu_{1}^{\mathrm{U}} \neq \cdots \neq \mu_{\mathrm{n}}^{\mathrm{U}}$.

\section{Between treatments:}

The null hypothesis for lower level model:

$\mathrm{H}_{0}^{\mathrm{L}}: \mu_{1}^{\mathrm{L}}=\mu_{1}^{\mathrm{L}}=\cdots=\mu_{\mathrm{n}}^{\mathrm{L}}$ against the alternative hypothesis $\mathrm{H}_{\mathrm{A}}^{\mathrm{L}}: \mu_{1}^{\mathrm{L}} \neq \mu_{1}^{\mathrm{L}} \neq \cdots \neq \mu_{\mathrm{n}}^{\mathrm{L}}$.

The null hypothesis for upper level model:

$\mathrm{H}_{0}^{\mathrm{U}}: \mu_{1}^{\mathrm{U}}=\mu_{1}^{\mathrm{U}}=\cdots=\mu_{\mathrm{n}}^{\mathrm{U}}$ against the alternative hypothesis $\mathrm{H}_{\mathrm{A}}^{\mathrm{U}}: \mu_{1}^{\mathrm{U}} \neq \mu_{1}^{\mathrm{U}} \neq \cdots \neq \mu_{\mathrm{n}}^{\mathrm{U}}$.

\section{Decision rules}

\section{Lower level model:}

(i) If $\mathrm{F}_{\text {Row }}^{\mathrm{L}}<\mathrm{F}_{\mathrm{t}}$ at ' $\mathrm{r}$ ' level of significance with ((n-1),(n-1)(n-2)) degrees of freedom, then the null hypothesis $\mathrm{H}_{0}^{\mathrm{L}}$ is accepted for certain value of $\alpha \in[0,1]$, otherwise the alternative hypothesis $\mathrm{H}_{\mathrm{A}}^{\mathrm{L}}$ is accepted.

(ii) If $\mathrm{F}_{\text {Col. }}^{\mathrm{L}}<\mathrm{F}_{\mathrm{t}}$ at ' $\mathrm{r}$ ' level of significance with ((n-1),(n-1)(n-2)) degrees of freedom, then the null hypothesis $\mathrm{H}_{0}^{\mathrm{L}}$ is accepted for certain value of $\alpha \in[0,1]$, otherwise the alternative hypothesis $\mathrm{H}_{\mathrm{A}}^{\mathrm{L}}$ is accepted.

(iii) If $\mathrm{F}_{\text {Treat. }}^{\mathrm{L}}<\mathrm{F}_{\mathrm{t}}$ at ' $\mathrm{r}$ ' level of significance with $((\mathrm{n}-1),(\mathrm{n}-1)(\mathrm{n}-2))$ degrees of freedom, then the null hypothesis $\mathrm{H}_{0}^{\mathrm{L}}$ is accepted for certain value of $\alpha \in[0,1]$, otherwise the alternative hypothesis $\mathrm{H}_{\mathrm{A}}^{\mathrm{L}}$ is accepted.

\section{Upper level model:}

(i) If $\mathrm{F}_{\mathrm{Row}}^{\mathrm{U}}<\mathrm{F}_{\mathrm{t}}$ at ' $\mathrm{r}$ ' level of significance with ((n-1),(n-1)(n-2)) degrees of freedom, then the null hypothesis $\mathrm{H}_{0}^{\mathrm{U}}$ is accepted for certain value of $\alpha \in[0,1]$, otherwise the alternative hypothesis $\mathrm{H}_{\mathrm{A}}^{\mathrm{U}}$ is accepted.

(ii) If $\mathrm{F}_{\text {Col. }}^{\mathrm{U}}<\mathrm{F}_{\mathrm{t}}$ at ' $\mathrm{r}$ ' level of significance with $((\mathrm{n}-1),(\mathrm{n}-1)(\mathrm{n}-2))$ degrees of freedom, then the null hypothesis $\mathrm{H}_{0}^{\mathrm{U}}$ is accepted for certain value of $\alpha \in[0,1]$, otherwise the alternative hypothesis $\mathrm{H}_{\mathrm{A}}^{\mathrm{U}}$ is accepted.

(iii) If $\mathrm{F}_{\text {Treat. }}^{\mathrm{U}}<\mathrm{F}_{\mathrm{t}}$ at ' $\mathrm{r}$ ' level of significance with $((\mathrm{n}-1),(\mathrm{n}-1)(\mathrm{n}-2))$ degrees of freedom, then the null hypothesis $\mathrm{H}_{0}^{\mathrm{L}}$ is accepted for certain value of $\alpha \in[0,1]$, otherwise the alternative hypothesis $\mathrm{H}_{\mathrm{A}}^{\mathrm{U}}$ is accepted.

\section{Conclusion table:}

\begin{tabular}{|l|l|l|}
\hline \multicolumn{3}{|c|}{ Acceptance of null hypotheses $\widetilde{\mathrm{H}}_{0}$} \\
\hline Lower Level Model & Upper Level Model & Conclusion \\
\hline $\begin{array}{l}\text { If } \mathrm{H}_{0} \text { is accepted for all } \alpha \\
\alpha \in[0,1]\end{array}$ & $\begin{array}{l}\text { and } \mathrm{H}_{0} \text { is accepted for all } \alpha \\
\alpha \in[0,1]\end{array}$ & $\begin{array}{l}\text { then } \widetilde{\mathrm{H}}_{0} \text { is accepted for all } \alpha \\
\alpha \in[0,1]\end{array}$ \\
\hline If $\mathrm{H}_{0}$ is accepted for all $\alpha$ & and $\mathrm{H}_{0}$ is rejected for all $\alpha$ & then $\widetilde{\mathrm{H}}_{0}$ is rejected for all $\alpha$ \\
$\alpha \in[0,1]$ & $\alpha \in[0,1]$ & $\alpha \in[0,1]$ \\
\hline If $\mathrm{H}_{0}$ is rejected for all $\alpha$ & and $\mathrm{H}_{0}$ is accepted for all $\alpha$ & then $\widetilde{\mathrm{H}}_{0}$ is rejected for all $\alpha$ \\
$\alpha \in[0,1]$ & $\alpha \in[0,1]$ & $\alpha \in[0,1]$ \\
\hline If $\mathrm{H}_{0}$ is rejected for all $\alpha$ & and $\mathrm{H}_{0}$ is rejected for all $\alpha$ & then $\widetilde{\mathrm{H}}_{0}$ is rejected for all $\alpha$ \\
$\alpha \in[0,1]$ & $\alpha \in[0,1]$ & $\alpha \in[0,1]$ \\
\hline
\end{tabular}

Partial acceptance of null hypothesis $\mathrm{H}_{0}$ at the intersection of certain level of $\alpha$ at both upper level and lower level models can be taken into account for the acceptance of the null hypothesis $\widetilde{\mathrm{H}}_{0}$. 


\section{Example-1}

The following observed data are the yields (in kgs.) of paddy where $A_{i}, i=1,2,3,4$ denote the different methods of cultivation. Due to some imprecise observations, the data recorded are in terms of trapezoidal fuzzy numbers. We examine whether the different methods of cultivation have given significantly different yields.

\begin{tabular}{|l|l|l|l|}
\hline $\mathrm{A}_{3}(22,23,25,27)$ & $\mathrm{A}_{2}(20,22,23,25)$ & $\mathrm{A}_{1}(15,17,18,20)$ & $\mathrm{A}_{4}(17,19,20,22)$ \\
\hline $\mathrm{A}_{1}(16,18,19,21)$ & $\mathrm{A}_{4}(15,16,18,19)$ & $\mathrm{A}_{3}(19,21,23,24)$ & $\mathrm{A}_{2}(15,17,18,20)$ \\
\hline $\mathrm{A}_{2}(17,19,20,22)$ & $\mathrm{A}_{1}(10,12,14,15)$ & $\mathrm{A}_{4}(14,16,17,19)$ & $\mathrm{A}_{3}(18,20,21,24)$ \\
\hline $\mathrm{A}_{4}(13,15,16,17)$ & $\mathrm{A}_{3}(15,17,19,20)$ & $\mathrm{A}_{2}(19,21,22,24)$ & $\mathrm{A}_{1}(10,13,15,16)$ \\
\hline
\end{tabular}

\section{Example-2}

The following is the effectiveness of three teaching methods $A_{1}, A_{2}$, and $A_{3}$ from the achievement scores given below tabulated age and aptitude wise. The collected data are in terms of trapezoidal fuzzy numbers due to some vague observations. We perform the variance analysis taking $\mathrm{A}_{1}, \mathrm{~A}_{2}$ and $A_{3}$ into account to test whether there is a significant difference among the 3 teaching methods.

\begin{tabular}{|l|c|c|c|}
\hline \multirow{2}{*}{ Aptitude } & \multicolumn{3}{|c|}{ Age } \\
\cline { 2 - 4 } & Young & Middle & Old \\
\hline Low & $\mathrm{A}_{1}(77,79,82,85)$ & $\mathrm{A}_{2}(82,85,87,88)$ & $\mathrm{A}_{3}(77,80,82,85)$ \\
\hline Medium & $\mathrm{A}_{2}(87,90,92,95)$ & $\mathrm{A}_{3}(78,81,82,85)$ & $\mathrm{A}_{1}(76,79,81,84)$ \\
\hline High & $\mathrm{A}_{3}(86,87,90,94)$ & $\mathrm{A}_{1}(80,83,84,87)$ & $\mathrm{A}_{2}(85,88,89,92)$ \\
\hline
\end{tabular}

\section{Three-way ANOVA test using alpha cut interval method}

Example 5.1. Let us consider example-1, the interval form of given tfns. using $\alpha$-cut method is given below:

\begin{tabular}{|c|c|c|c|}
\hline $\mathrm{A}_{3}[22+\alpha, 27-2 \alpha]$ & $\mathrm{A}_{2}[20+2 \alpha, 25-2 \alpha]$ & $\mathrm{A}_{1}[15+2 \alpha, 20-2 \alpha]$ & $\mathrm{A}_{4}[17+2 \alpha, 22-2 \alpha]$ \\
\hline $\mathrm{A}_{1}[16+2 \alpha, 21-2 \alpha]$ & $\mathrm{A}_{4}[15+\alpha, 19-\alpha]$ & $\mathrm{A}_{3}[19+2 \alpha, 24-\alpha]$ & $\mathrm{A}_{2}[15+2 \alpha, 20-2 \alpha]$ \\
\hline $\mathrm{A}_{2}[17+2 \alpha, 22-2 \alpha]$ & $\mathrm{A}_{1}[10+2 \alpha, 15-\alpha]$ & $\mathrm{A}_{4}[14+2 \alpha, 19-2 \alpha]$ & $\mathrm{A}_{3}[18+2 \alpha, 24-3 \alpha]$ \\
\hline $\mathrm{A}_{4}[13+2 \alpha, 17-\alpha]$ & $\mathrm{A}_{3}[15+2 \alpha, 20-\alpha]$ & $\mathrm{A}_{2}[19+2 \alpha, 24-2 \alpha]$ & $\mathrm{A}_{1}[10+3 \alpha, 16-\alpha]$ \\
\hline
\end{tabular}

The upper level model and lower level model $[16,17]$ can be constructed using the descriptions (3.1). Here we have noted only the three-way ANOVA calculated results by omitting repeated tables and surplus explanations.

For lower level model: $Q^{\mathrm{L}}=\left(47 \alpha^{2}-354 \alpha+2639\right) / 16, \quad(\mathrm{n}-1)=3 ; \mathrm{Q}_{1}^{\mathrm{L}}=\left(11 \alpha^{2}-146 \alpha+699\right) / 16$, $(\mathrm{n}-1)=3 ; \mathrm{Q}_{2}^{\mathrm{L}}=\left(11 \alpha^{2}-34 \alpha+227\right) / 16, \quad(\mathrm{n}-1)=3 ; \quad \mathrm{Q}_{3}^{\mathrm{L}}=\left(11 \alpha^{2}-146 \alpha+1371\right) / 16, \quad(\mathrm{n}-1)=3 \quad$ and $\mathrm{Q}_{4}^{\mathrm{L}}=\left(7 \alpha^{2}-14 \alpha+171\right) / 8,(\mathrm{n}-1)(\mathrm{n}-2)=6$.

Between rows: $\mathrm{F}_{\mathrm{R}}^{\mathrm{L}}=\frac{\mathrm{M}_{1}^{\mathrm{L}}}{\mathrm{M}_{4}^{\mathrm{L}}}=\frac{11 \alpha^{2}-146 \alpha+699}{7 \alpha^{2}-14 \alpha+171} ; 0 \leq \alpha \leq 1$. Now, from F-tables, $\mathrm{F}_{\mathrm{t}(5 \%)}(3,6)=4.76$. Here $\mathrm{F}_{\mathrm{R}}^{\mathrm{L}}<\mathrm{F}_{\mathrm{t}(5 \%)}, \forall \alpha, \alpha \in[0,1] . \Rightarrow$ The null hypothesis $\mathrm{H}_{0}^{\mathrm{L}}$ is accepted at $5 \%$ level of significance. $\Rightarrow$ The difference between rows is not significant.

Between columns: $\mathrm{F}_{\mathrm{C}}^{\mathrm{L}}=\frac{\mathrm{M}_{2}^{\mathrm{L}}}{\mathrm{M}_{4}^{\mathrm{L}}}=\frac{11 \alpha^{2}-34 \alpha+227}{7 \alpha^{2}-14 \alpha+171} ; 0 \leq \alpha \leq 1$. Now, from F-tables, $\mathrm{F}_{\mathrm{t}(5 \%)}(3,6)=4.76$.

Here $\mathrm{F}_{\mathrm{C}}^{\mathrm{L}}<\mathrm{F}_{\mathrm{t}(5 \%)}, \forall \alpha, \alpha \in[0,1] . \Rightarrow$ The null hypothesis $\mathrm{H}_{0}^{\mathrm{L}}$ is accepted at $5 \%$ level of significance. $\Rightarrow$ The difference between columns is not significant. 
Between treatments: $\quad \mathrm{F}_{\mathrm{T}}^{\mathrm{L}}=\frac{\mathrm{M}_{3}^{\mathrm{L}}}{\mathrm{M}_{4}^{\mathrm{L}}}=\frac{11 \alpha^{2}-146 \alpha+1371}{7 \alpha^{2}-14 \alpha+171} ; \quad 0 \leq \alpha \leq 1 . \quad$ Now, from F-tables, $\mathrm{F}_{\mathrm{t}(5 \%)}(3,6)=4.76$. Here $\mathrm{F}_{\mathrm{T}}^{\mathrm{L}}>\mathrm{F}_{\mathrm{t}(5 \%)}, \forall \alpha, \alpha \in[0,1] . \Rightarrow$ The null hypothesis $\mathrm{H}_{0}^{\mathrm{L}}$ is rejected at $5 \%$ level of significance. $\Rightarrow$ The difference between treatments is significant. $\Rightarrow$ There is a significant difference among the methods of cultivation.

For upper level model: $Q^{U}=\left(87 \alpha^{2}-566 \alpha+2703\right) / 16, \quad(n-1)=3 ; Q_{1}^{U}=\left(27 \alpha^{2}-158 \alpha+659\right) / 16$, $(\mathrm{n}-1)=3 ; \quad \mathrm{Q}_{2}^{\mathrm{U}}=\left(19 \alpha^{2}-62 \alpha+187\right) / 16, \quad(\mathrm{n}-1)=3 ; \quad \mathrm{Q}_{3}^{\mathrm{U}}=\left(11 \alpha^{2}-206 \alpha+1451\right) / 16, \quad(\mathrm{n}-1)=3 \quad$ and $\mathrm{Q}_{4}^{\mathrm{U}}=\left(15 \alpha^{2}-70 \alpha+203\right) / 8,(\mathrm{n}-1)(\mathrm{n}-2)=6$.

Between rows: $\mathrm{F}_{\mathrm{R}}^{\mathrm{U}}=\frac{\mathrm{M}_{1}^{\mathrm{U}}}{\mathrm{M}_{4}^{\mathrm{U}}}=\frac{27 \alpha^{2}-158 \alpha+659}{15 \alpha^{2}-70 \alpha+203} ; 0 \leq \alpha \leq 1$. Now, from F-tables, $\mathrm{F}_{\mathrm{t}(5 \%)}(3,6)=4.76$. Here $\mathrm{F}_{\mathrm{R}}^{\mathrm{U}}<\mathrm{F}_{\mathrm{t}(5 \%)}, \forall \alpha, \alpha \in[0,1] . \Rightarrow$ The null hypothesis $\mathrm{H}_{0}^{\mathrm{U}}$ is accepted at $5 \%$ level of significance. $\Rightarrow$ The difference between rows is not significant.

Between columns: $F_{C}^{U}=\frac{M_{4}^{U}}{M_{2}^{U}}=\frac{15 \alpha^{2}-70 \alpha+203}{19 \alpha^{2}-62 \alpha+187} ; 0 \leq \alpha \leq 1$. Now, from F-tables, $F_{t(5 \%)}(6,3)=8.94$.

Here $\mathrm{F}_{\mathrm{C}}^{\mathrm{U}}<\mathrm{F}_{\mathrm{t}(5 \%)}, \forall \alpha, \alpha \in[0,1] . \Rightarrow$ The null hypothesis $\mathrm{H}_{0}^{\mathrm{U}}$ is accepted at $5 \%$ level of significance. $\Rightarrow$ The difference between columns is not significant.

Between treatments: $\quad \mathrm{F}_{\mathrm{T}}^{\mathrm{U}}=\frac{\mathrm{M}_{3}^{\mathrm{U}}}{\mathrm{M}_{4}^{\mathrm{U}}}=\frac{11 \alpha^{2}-206 \alpha+1451}{15 \alpha^{2}-70 \alpha+203} ; \quad 0 \leq \alpha \leq 1$. Now, from F-tables, $\mathrm{F}_{\mathrm{t}(5 \%)}(3,6)=4.76$. Here $\mathrm{F}_{\mathrm{T}}^{\mathrm{U}}>\mathrm{F}_{\mathrm{t}(5 \%)}, \forall \alpha, \alpha \in[0,1] . \Rightarrow$ The null hypothesis $\mathrm{H}_{0}^{\mathrm{U}}$ is rejected at $5 \%$ level of significance. $\Rightarrow$ The difference between treatments is significant. $\Rightarrow$ There is a significant difference among the methods of cultivation.

Hence, from the decisions obtained from both lower and upper level models, we conclude that there is a significance difference among the methods of cultivation.

Example 5.2. Let us consider example-2, the interval form of given tfns. using $\alpha$-cut method is given below:

\begin{tabular}{|l|l|c|c|}
\hline \multirow{2}{*}{ Aptitude } & \multicolumn{3}{|c|}{ Age } \\
\cline { 2 - 4 } & \multicolumn{1}{|c|}{ Young } & Middle & Old \\
\hline Low & {$[77+2 \alpha, 85-3 \alpha]$} & {$[82+3 \alpha, 88-\alpha]$} & {$[77+3 \alpha, 85-3 \alpha]$} \\
\hline Medium & {$[87+3 \alpha, 95-3 \alpha]$} & {$[78+3 \alpha, 85-3 \alpha]$} & {$[76+3 \alpha, 84-3 \alpha]$} \\
\hline High & {$[86+\alpha, 94-4 \alpha]$} & {$[80+3 \alpha, 87-3 \alpha]$} & {$[85+3 \alpha, 92-3 \alpha]$} \\
\hline
\end{tabular}

For lower level model: $Q^{L}=\left(36 \alpha^{2}-114 \alpha+1304\right) / 9,(n-1)=2 ; Q_{1}^{L}=\left(6 \alpha^{2}-60 \alpha+350\right) / 9$, $(n-1)=2$; $\mathrm{Q}_{2}^{\mathrm{L}}=\left(18 \alpha^{2}-132 \alpha+248\right) / 9, \quad(\mathrm{n}-1)=2 ; \mathrm{Q}_{3}^{\mathrm{L}}=\left(6 \alpha^{2}+78 \alpha+674\right) / 9, \quad(\mathrm{n}-1)=2$ and $\mathrm{Q}_{4}^{\mathrm{L}}=\left(6 \alpha^{2}+32\right) / 9$, $(\mathrm{n}-1)(\mathrm{n}-2)=2$.

Between rows: $F_{R}^{L}=\frac{M_{1}^{L}}{M_{4}^{L}}=\frac{6 \alpha^{2}-60 \alpha+350}{6 \alpha^{2}+32} ; 0 \leq \alpha \leq 1$. Now, from F-tables, $F_{t(5 \%)}(2,2)=19.00$. Here $\mathrm{F}_{\mathrm{R}}^{\mathrm{L}}<\mathrm{F}_{\mathrm{t}(5 \%)}, \forall \alpha, \alpha \in[0,1] . \Rightarrow$ The null hypothesis $\mathrm{H}_{0}^{\mathrm{L}}$ is accepted at $5 \%$ level of significance. $\Rightarrow$ The difference between rows is not significant.

Between columns: $\mathrm{F}_{\mathrm{C}}^{\mathrm{L}}=\frac{\mathrm{M}_{2}^{\mathrm{L}}}{\mathrm{M}_{4}^{\mathrm{L}}}=\frac{18 \alpha^{2}-132 \alpha+248}{6 \alpha^{2}+32} ; 0 \leq \alpha \leq 1$. Now, from F-tables, $\mathrm{F}_{\mathrm{t}(5 \%)}(2,2)=19.00$. Here $\mathrm{F}_{\mathrm{C}}^{\mathrm{L}}<\mathrm{F}_{\mathrm{t}(5 \%)}, \forall \alpha, \alpha \in[0,1] . \Rightarrow$ The null hypothesis $\mathrm{H}_{0}^{\mathrm{L}}$ is accepted at $5 \%$ level of significance. $\Rightarrow$ The difference between columns is not significant. 
Between treatments: $\quad \mathrm{F}_{\mathrm{T}}^{\mathrm{L}}=\frac{\mathrm{M}_{3}^{\mathrm{L}}}{\mathrm{M}_{4}^{\mathrm{L}}}=\frac{6 \alpha^{2}+78 \alpha+674}{6 \alpha^{2}+32} ; \quad 0 \leq \alpha \leq 1 . \quad$ Now, from F-tables, $\mathrm{F}_{\mathrm{t}(5 \%)}(2,2)=19.00$. Here $\mathrm{F}_{\mathrm{T}}^{\mathrm{L}}>\mathrm{F}_{\mathrm{t}(5 \%)}, \forall \alpha, \alpha \in[0,1] . \Rightarrow$ The null hypothesis $\mathrm{H}_{0}^{\mathrm{L}}$ is rejected at $5 \%$ level of significance. $\Rightarrow$ The difference between treatments is significant. $\Rightarrow$ There is a significant difference among the three teaching methods.

For upper level model: $Q^{U}=\left(44 \alpha^{2}-114 \alpha+1296\right) / 9, \quad(n-1)=2 ; \quad Q_{1}^{U}=\left(14 \alpha^{2}-132 \alpha+342\right) / 9$, $(\mathrm{n}-1)=2 ; \quad \mathrm{Q}_{2}^{\mathrm{U}}=\left(14 \alpha^{2}-114 \alpha+366\right) / 9, \quad(\mathrm{n}-1)=2 ; \quad \mathrm{Q}_{3}^{\mathrm{U}}=\left(14 \alpha^{2}+126 \alpha+546\right) / 9, \quad(\mathrm{n}-1)=2 \quad$ and $\mathrm{Q}_{4}^{\mathrm{U}}=\left(2 \alpha^{2}+6 \alpha+42\right) / 9,(\mathrm{n}-1)(\mathrm{n}-2)=2$.

Between rows: $\mathrm{F}_{\mathrm{R}}^{\mathrm{U}}=\frac{\mathrm{M}_{1}^{\mathrm{U}}}{\mathrm{M}_{4}^{\mathrm{U}}}=\frac{14 \alpha^{2}-132 \alpha+342}{2 \alpha^{2}+6 \alpha+42} ; 0 \leq \alpha \leq 1$. Now, from F-tables, $\mathrm{F}_{\mathrm{t}(5 \%)}(2,2)=19.00$. Here $\mathrm{F}_{\mathrm{R}}^{\mathrm{U}}<\mathrm{F}_{\mathrm{t}(5 \%)}, \forall \alpha, \alpha \in[0,1] . \Rightarrow$ The null hypothesis $\mathrm{H}_{0}^{\mathrm{U}}$ is accepted at $5 \%$ level of significance. $\Rightarrow$ The difference between rows is not significant.

Between columns: $\mathrm{F}_{\mathrm{C}}^{\mathrm{U}}=\frac{\mathrm{M}_{2}^{\mathrm{U}}}{\mathrm{M}_{4}^{\mathrm{U}}}=\frac{14 \alpha^{2}-114 \alpha+366}{2 \alpha^{2}+6 \alpha+42} ; 0 \leq \alpha \leq 1$. Now, from F-tables, $\mathrm{F}_{\mathrm{t}(5 \%)}(2,2)=19.00$. Here $\mathrm{F}_{\mathrm{C}}^{\mathrm{U}}<\mathrm{F}_{\mathrm{t}(5 \%)}, \forall \alpha, \alpha \in[0,1] . \Rightarrow$ The null hypothesis $\mathrm{H}_{0}^{\mathrm{U}}$ is accepted at $5 \%$ level of significance. $\Rightarrow$ The difference between columns is not significant.

Between treatments: $\quad \mathrm{F}_{\mathrm{T}}^{\mathrm{U}}=\frac{\mathrm{M}_{3}^{\mathrm{U}}}{\mathrm{M}_{4}^{\mathrm{U}}}=\frac{14 \alpha^{2}+126 \alpha+546}{2 \alpha^{2}+6 \alpha+42} ; \quad 0 \leq \alpha \leq 1 . \quad$ Now, from F-tables, $\mathrm{F}_{\mathrm{t}(5 \%)}(2,2)=19.00$. Here $\mathrm{F}_{\mathrm{T}}^{\mathrm{U}}<\mathrm{F}_{\mathrm{t}(5 \%)}, \forall \alpha, \alpha \in[0,1] . \Rightarrow$ The null hypothesis $\mathrm{H}_{0}^{\mathrm{U}}$ is accepted at $5 \%$ level of significance. $\Rightarrow$ The difference between treatments is not significant. $\Rightarrow$ The difference among the three teaching methods is not significant.

Here, the obtained decisions through lower and upper level models do not provide parallel discussion. In lower level model, between treatments, the null hypothesis is rejected and in the upper level model, between treatments, the null hypothesis is accepted. Hence the null hypothesis is rejected between treatments. Now, the CRD, RBD and LSD are independent of origin which implies that the arithmetic operations such as addition/subtraction/multiplication or division by non-zero quantity can be performed among the observed data uniformly for all entries in order to simplify the large numerical calculations while the observed data are numerically large. This indicates that ANOVA test stands on the magnitude ratio among each data of the sample observations. The another idea in this paper is, when the test is conducted using natural and vague observations such as fuzzy numbers for instance, we may use ranking grades for all observed fuzzy numbers by using unique method without damaging the magnitude ratios among the fuzzy samples. In fact, the ranking grades of all fuzzy numbers using fuzzy analytic method are crisp in nature and we perform the LSD test as usual and better decisions can be obtained.

\section{Wang's centroid point and ranking method}

Wang et al. [25] found that the centroid formulae proposed by Cheng are incorrect and have led to some misapplications such as by Chu and Tsao. They presented the correct method for centroid formulae for a generalized fuzzy number $\widetilde{A}=(a, b, c, d ; w)$ as

$$
\left(\overline{\mathrm{x}}_{0}, \overline{\mathrm{y}}_{0}\right)=\left[\frac{1}{3}\left((\mathrm{a}+\mathrm{b}+\mathrm{c}+\mathrm{d})-\left(\frac{\mathrm{dc}-\mathrm{ab}}{(\mathrm{d}+\mathrm{c})-(\mathrm{a}+\mathrm{b})}\right)\right),\left(\frac{\mathrm{w}}{3}\right)\left(1+\left(\frac{\mathrm{c}-\mathrm{b}}{(\mathrm{d}+\mathrm{c})-(\mathrm{a}+\mathrm{b})}\right)\right)\right]
$$


And the ranking function associated with $\widetilde{\mathrm{A}}$ is

$$
\mathrm{R}(\widetilde{\mathrm{A}})=\sqrt{\overline{\mathrm{x}_{0}^{2}+\overline{\mathrm{y}}_{0}^{2}}}
$$

For a normalized $\mathrm{tfn}$, we put $\mathrm{w}=1$ in equations (6.1) so we have,

$$
\left(\overline{\mathrm{x}}_{0}, \overline{\mathrm{y}}_{0}\right)=\left[\frac{1}{3}\left((\mathrm{a}+\mathrm{b}+\mathrm{c}+\mathrm{d})-\left(\frac{\mathrm{dc}-\mathrm{ab}}{(\mathrm{d}+\mathrm{c})-(\mathrm{a}+\mathrm{b})}\right)\right),\left(\frac{1}{3}\right)\left(1+\left(\frac{\mathrm{c}-\mathrm{b}}{(\mathrm{d}+\mathrm{c})-(\mathrm{a}+\mathrm{b})}\right)\right)\right]
$$

And the ranking function associated with $\widetilde{\mathrm{A}}$ is $\quad \mathrm{R}(\widetilde{\mathrm{A}})=\sqrt{-\mathrm{x}_{0}^{2}+\overline{\mathrm{y}}_{0}^{2}}$

Let $\widetilde{\mathrm{A}}_{i}$ and $\widetilde{\mathrm{A}}_{j}$ be two fuzzy numbers, (i) $R\left(\widetilde{\mathrm{A}}_{i}\right)>\mathrm{R}\left(\widetilde{\mathrm{A}}_{j}\right)$ then $\widetilde{\mathrm{A}}_{i}>\widetilde{\mathrm{A}}_{j}$

(ii) $R\left(\widetilde{\mathrm{A}}_{i}\right)>\mathrm{R}\left(\widetilde{\mathrm{A}}_{\mathrm{j}}\right)$ then $\widetilde{\mathrm{A}}_{i}>\widetilde{\mathrm{A}}_{j}$ and (iii) $\mathrm{R}\left(\widetilde{\mathrm{A}}_{i}\right)=\mathrm{R}\left(\widetilde{\mathrm{A}}_{j}\right)$ then $\widetilde{\mathrm{A}}_{i}=\widetilde{\mathrm{A}}_{j}$.

Example 6.1. Let we consider example 1, using the above relations (6.3) and (6.4), we obtain the ranks of tfns. which are tabulated below:

\begin{tabular}{|l|l|l|l|}
\hline \multicolumn{4}{|c|}{$\mathrm{R}\left(\widetilde{\mathrm{A}}_{\mathrm{i}}\right) ; \mathrm{i}=1,2,3,4}$. \\
\hline $\mathrm{A}_{3}(24.2895)$ & $\mathrm{A}_{2}(22.5034)$ & $\mathrm{A}_{1}(17.5043)$ & $\mathrm{A}_{4}(19.5039)$ \\
\hline $\mathrm{A}_{1}(18.5041)$ & $\mathrm{A}_{4}(17.0058)$ & $\mathrm{A}_{3}(21.7185)$ & $\mathrm{A}_{2}(17.5043)$ \\
\hline $\mathrm{A}_{2}(19.5039)$ & $\mathrm{A}_{1}(12.7215)$ & $\mathrm{A}_{4}(16.5046)$ & $\mathrm{A}_{3}(20.8130)$ \\
\hline $\mathrm{A}_{4}(15.2053)$ & $\mathrm{A}_{3}(17.7195)$ & $\mathrm{A}_{2}(21.5035)$ & $\mathrm{A}_{1}(13.4231)$ \\
\hline
\end{tabular}

The ANOVA table values of tfns. using Wang's Centroid Point:

Here, $\mathrm{Q}=155.12 ; \mathrm{Q}_{1}=38.5624, \mathrm{n}-1=3 ; \mathrm{Q}_{2}=11.674, \mathrm{n}-1=3 ; \mathrm{Q}_{3}=83.5525, \mathrm{n}-1=3 ; \mathrm{Q}_{4}=21.3307$, $(n-1)(n-2)=6$ and variance ratio of $F$ can be calculated as per the description of the ANOVA table noted in section-4. Now, $\mathrm{F}_{\text {Row }}=3.61, \mathrm{~F}_{\mathrm{t}(5 \%)}(3,6)=4.76$. And $\mathrm{F}_{\text {Row }}<\mathrm{F}_{\mathrm{t}(5 \%)} . \Rightarrow$ The null hypothesis $\widetilde{\mathrm{H}}_{0}$ is accepted at $5 \%$ level of significance. $\Rightarrow$ The difference between rows is not significant. $\mathrm{F}_{\text {Col. }}=1.09, \mathrm{~F}_{\mathrm{t}(5 \%)}(3,6)=4.76$. And $\mathrm{F}_{\mathrm{Col}}<\mathrm{F}_{\mathrm{t}(5 \%)} . \Rightarrow$ The null hypothesis $\widetilde{\mathrm{H}}_{0}$ is accepted at $5 \%$ level of significance. $\Rightarrow$ The difference between columns is not significant. $\mathrm{F}_{\text {Treat. }}=7.82, \mathrm{~F}_{\mathrm{t}(5 \%)}(3,6)=4.76$. And $\mathrm{F}_{\text {Treat. }}>\mathrm{F}_{\mathrm{t}(5 \%)} . \Rightarrow$ The null hypothesis $\widetilde{\mathrm{H}}_{0}$ is rejected at $5 \%$ level of significance. $\Rightarrow$ The difference between treatments is significant. $\Rightarrow$ There is a significant difference among the methods of cultivation.

Example 6.2. Let we consider example 2, using the above relations (6.3) and (6.4), we obtain the ranks of tfns. which are tabulated below:

\begin{tabular}{|l|c|c|c|}
\hline \multirow{2}{*}{ Aptitude } & \multicolumn{3}{|c|}{$\mathrm{R}\left(\widetilde{\mathrm{A}}_{\mathrm{i}}\right) ; \mathrm{i}=1,2,3}$. \\
\cline { 2 - 4 } & Young & Middle & Old \\
\hline Low & $\mathrm{A}_{1}(80.78899)$ & $\mathrm{A}_{2}(85.41768)$ & $\mathrm{A}_{3}(81.00099)$ \\
\hline Medium & $\mathrm{A}_{2}(91.00088)$ & $\mathrm{A}_{3}(81.50086)$ & $\mathrm{A}_{1}(80.001)$ \\
\hline High & $\mathrm{A}_{3}(89.36464)$ & $\mathrm{A}_{1}(83.50084)$ & $\mathrm{A}_{2}(88.50079)$ \\
\hline
\end{tabular}

The ANOVA table values of tfns. using Wang's Centroid Point:

Here, $\quad \mathrm{Q}=138.9865 ; \mathrm{Q}_{1}=34.1185, \mathrm{n}-1=2 ; \quad \mathrm{Q}_{2}=27.9829, \quad \mathrm{n}-1=2 ; \quad \mathrm{Q}_{3}=72.5893, \quad \mathrm{n}-1=2$; $\mathrm{Q}_{4}=4.2958$, $(\mathrm{n}-1)(\mathrm{n}-2)=2$ and variance ratio of $\mathrm{F}$ can be calculated as per the description of the ANOVA table noted in section-4. Now, $\mathrm{F}_{\text {Row }}=7.9423, \mathrm{~F}_{\mathrm{t}(5 \%)}(2,2)=19.00$. And $\mathrm{F}_{\mathrm{Row}}<\mathrm{F}_{\mathrm{t}(5 \%)}$. $\Rightarrow$ 
The null hypothesis $\widetilde{\mathrm{H}}_{0}$ is accepted at 5\% level of significance. $\Rightarrow$ The difference between rows is not significant. $\mathrm{F}_{\mathrm{Col}}=6.5140, \mathrm{~F}_{\mathrm{t}(5 \%)}(2,2)=19.00$. And $\mathrm{F}_{\mathrm{Col} .}<\mathrm{F}_{\mathrm{t}(5 \%)} . \Rightarrow$ The null hypothesis $\widetilde{\mathrm{H}}_{0}$ is accepted at $5 \%$ level of significance. $\Rightarrow$ The difference between columns is not significant. $\mathrm{F}_{\text {Treat. }}=16.8978, \mathrm{~F}_{\mathrm{t}(5 \%)}(2,2)=19.00$. And $\mathrm{F}_{\text {Treat. }}<\mathrm{F}_{\mathrm{t}(5 \%)} . \Rightarrow$ The null hypothesis $\widetilde{\mathrm{H}}_{0}$ is accepted at $5 \%$ level of significance. $\Rightarrow$ The difference between treatments is not significant. $\Rightarrow$ The difference among the three teaching methods is not significant.

\section{Rezvani's ranking function of tfns.}

The centroid of a trapezoid is considered as the balancing point of the trapezoid. Divide the trapezoid into three plane figures. These three plane figures are a triangle (APB), a rectangle (BPQC) and a triangle (CQD) respectively. Let the centroids of the three plane figures be $\mathrm{G}_{1}, \mathrm{G}_{2}$ and $\mathrm{G}_{3}$ respectively. The incenter of these centroids $\mathrm{G}_{1}, \mathrm{G}_{2}$ and $\mathrm{G}_{3}$ is taken as the point of reference to define the ranking of generalized trapezoidal fuzzy numbers. The reason for selecting this point as a point of reference is that each centroid point are balancing points of each individual plane figure and the incenter of these centroid points is much more balancing point for a generalized trapezoidal fuzzy number. Therefore, this point would be a better reference point than the centroid point of the trapezoid.

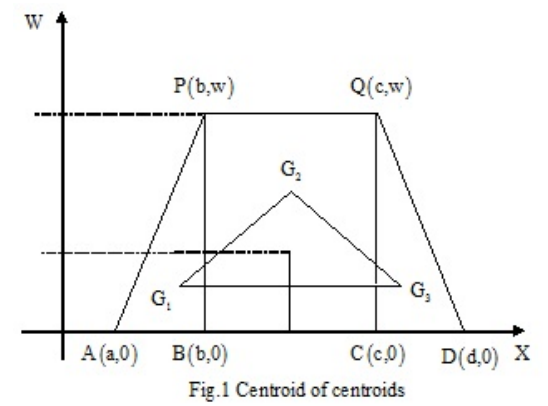

Consider a generalized trapezoidal fuzzy number $\widetilde{A}=(a, b, c, d ; w)$. The centroids of the three plane figures are:

$\mathrm{G}_{1}=\left(\frac{\mathrm{a}+2 \mathrm{~b}}{3}, \frac{\mathrm{w}}{3}\right), \mathrm{G}_{2}=\left(\frac{\mathrm{b}+\mathrm{c}}{2}, \frac{\mathrm{w}}{2}\right)$ and $\mathrm{G}_{3}=\left(\frac{2 \mathrm{c}+\mathrm{d}}{3}, \frac{\mathrm{w}}{3}\right)$

Equation of the line $G_{1} G_{3}$ is $y=\frac{w}{3}$ and $G_{2}$ does not lie on the line $G_{1} G_{3}$. Therefore, $\mathrm{G}_{1}, \mathrm{G}_{2}$ and $\mathrm{G}_{3}$ are non-collinear and they form a triangle. We define the incenter $\mathrm{I}\left(\overline{\mathrm{x}}_{0}, \overline{\mathrm{y}}_{0}\right)$ of the triangle with vertices $G_{1}, G_{2}$ and $G_{3}$ of the generalized fuzzy number $\widetilde{A}=(a, b, c, d ; w)$ as [20]

$$
\begin{gathered}
\mathrm{I}_{\widetilde{\mathrm{A}}}\left(\overline{\mathrm{x}}_{0}, \overline{\mathrm{y}}_{0}\right)=\left[\frac{\alpha\left(\frac{\mathrm{a}+2 \mathrm{~b}}{3}\right)+\beta\left(\frac{\mathrm{b}+\mathrm{c}}{2}\right)+\gamma\left(\frac{2 \mathrm{c}+\mathrm{d}}{3}\right)}{\alpha+\beta+\gamma}, \frac{\alpha\left(\frac{\mathrm{w}}{3}\right)+\beta\left(\frac{\mathrm{w}}{2}\right)+\gamma\left(\frac{\mathrm{w}}{3}\right)}{\alpha+\beta+\gamma}\right] \\
\text { where } \alpha=\frac{\sqrt{(\mathrm{c}-3 \mathrm{~b}+2 \mathrm{~d})^{2}+\mathrm{w}^{2}}}{6}, \beta=\frac{\sqrt{(2 \mathrm{c}+\mathrm{d}-\mathrm{a}-2 \mathrm{~b})^{2}}}{3}, \gamma=\frac{\sqrt{(3 \mathrm{c}-2 \mathrm{a}-\mathrm{b})^{2}+\mathrm{w}^{2}}}{6}
\end{gathered}
$$

And ranking function of the trapezoidal fuzzy number $\widetilde{A}=(a, b, c, d ; w)$ which maps the set of all fuzzy numbers to a set of all real numbers $[$ i.e. $R:[\widetilde{A}] \rightarrow \mathbb{R}]$ is defined as

$$
\mathrm{R}(\widetilde{\mathrm{A}})=\sqrt{\overline{\mathrm{x}_{0}^{2}+\overline{\mathrm{y}}_{0}^{2}}}
$$


which is the Euclidean distance from the incenter of the centroids. For a normalized tfn, we put $\mathrm{W}=1$ in equations (1), (2) and (3) so we have,

$$
\begin{aligned}
& \mathrm{G}_{1}=\left(\frac{\mathrm{a}+2 \mathrm{~b}}{3}, \frac{1}{3}\right), \mathrm{G}_{2}=\left(\frac{\mathrm{b}+\mathrm{c}}{2}, \frac{1}{2}\right) \text { and } \mathrm{G}_{3}=\left(\frac{2 \mathrm{c}+\mathrm{d}}{3}, \frac{1}{3}\right) \\
& \mathrm{I}_{\widetilde{\mathrm{A}}}\left(\overline{\mathrm{x}}_{0}, \overline{\mathrm{y}}_{0}\right)=\left[\frac{\alpha\left(\frac{\mathrm{a}+2 \mathrm{~b}}{3}\right)+\beta\left(\frac{\mathrm{b}+\mathrm{c}}{2}\right)+\gamma\left(\frac{2 \mathrm{c}+\mathrm{d}}{3}\right)}{\alpha+\beta+\gamma}, \frac{\left.\alpha\left(\frac{1}{3}\right)+\beta\left(\frac{1}{2}\right)+\gamma\left(\frac{1}{3}\right)\right]}{\alpha+\beta+\gamma}\right] \\
& \text { where } \alpha=\frac{\sqrt{(\mathrm{c}-3 \mathrm{~b}+2 \mathrm{~d})^{2}+1}}{6}, \beta=\frac{\sqrt{(2 \mathrm{c}+\mathrm{d}-\mathrm{a}-2 \mathrm{~b})^{2}}}{3} \text { and } \gamma=\frac{\sqrt{(3 \mathrm{c}-2 \mathrm{a}-\mathrm{b})^{2}+1}}{6}
\end{aligned}
$$

And ranking function of the trapezoidal fuzzy number $\widetilde{A}=(a, b, c, d ; 1)$ is defined as

$$
\mathrm{R}(\widetilde{\mathrm{A}})=\sqrt{\overline{\mathrm{x}}_{0}^{2}+\overline{\mathrm{y}}_{0}^{2}}
$$

\section{Three-way ANOVA test using Rezvani's ranking function}

We now analyse the three-way ANOVA test by assigning rank for each normalized trapezoidal fuzzy numbers and based on the ranking grades the decisions are observed.

Example 7.1. Let us consider example 1, using the above relations (7.4), (7.5) and (7.6), we get the ranks of each tfns. $\widetilde{A}_{i}$ as below:

\begin{tabular}{|c|c|c|c|}
\hline \multicolumn{4}{|c|}{$\mathrm{R}\left(\widetilde{\mathrm{A}}_{\mathrm{i}}\right) ; \mathrm{i}=1,2,3,4}$. \\
\hline $\mathrm{A}_{3}(24.0046)$ & $\mathrm{A}_{2}(22.5038)$ & $\mathrm{A}_{1}(17.5049)$ & $\mathrm{A}_{4}(19.5044)$ \\
\hline $\mathrm{A}_{1}(18.5047)$ & $\mathrm{A}_{4}(17.0051)$ & $\mathrm{A}_{3}(22.0029)$ & $\mathrm{A}_{2}(17.5049)$ \\
\hline $\mathrm{A}_{2}(19.5044)$ & $\mathrm{A}_{1}(13.0056)$ & $\mathrm{A}_{4}(16.5052)$ & $\mathrm{A}_{3}(20.5055)$ \\
\hline $\mathrm{A}_{4}(15.5033)$ & $\mathrm{A}_{3}(18.0038)$ & $\mathrm{A}_{2}(21.504)$ & $\mathrm{A}_{1}(14.0045)$ \\
\hline
\end{tabular}

The ANOVA table values of tfns. using Rezvani's Centroid Point:

Here, $\mathrm{Q}=141.412 ; \mathrm{Q}_{1}=34.0609, \mathrm{n}-1=3 ; \mathrm{Q}_{2}=10.6819, \mathrm{n}-1=3 ; \mathrm{Q}_{3}=77.5438, \mathrm{n}-1=3 ; \mathrm{Q}_{4}=19.1256$ , (n-1)(n-2) $=6$ and variance ratio of $F$ can be calculated as per the description of the ANOVA table noted in section-4. Now, $\mathrm{F}_{\mathrm{Row}}=3.56, \mathrm{~F}_{\mathrm{t}(5 \%)}(3,6)=4.76$. And $\mathrm{F}_{\mathrm{Row}}<\mathrm{F}_{\mathrm{t}(5 \%)}$. $\Rightarrow$ The null hypothesis $\widetilde{\mathrm{H}}_{0}$ is accepted at $5 \%$ level of significance. $\Rightarrow$ The difference between rows is not significant. $\mathrm{F}_{\text {Col. }}=1.12, \mathrm{~F}_{\mathrm{t}(5 \%)}(3,6)=4.76$. And $\mathrm{F}_{\mathrm{Col}}<\mathrm{F}_{\mathrm{t}(5 \%)} . \Rightarrow$ The null hypothesis $\widetilde{\mathrm{H}}_{0}$ is accepted at $5 \%$ level of significance. $\Rightarrow$ The difference between columns is not significant. $\mathrm{F}_{\text {Treat. }}=8.10, \mathrm{~F}_{\mathrm{t}(5 \%)}(3,6)=4.76$. And $\mathrm{F}_{\text {Treat. }}>\mathrm{F}_{\mathrm{t}(5 \%)} . \Rightarrow$ The null hypothesis $\widetilde{\mathrm{H}}_{0}$ is rejected at $5 \%$ level of significance. $\Rightarrow$ The difference between treatments is significant. $\Rightarrow$ There is a significant difference among the methods of cultivation.

Example 7.2. Let us consider example 2, using the above relations (7.4), (7.5) and (7.6), we get the ranks of each tfns. $\widetilde{A}_{i}$ as below:

\begin{tabular}{|l|c|c|c|}
\hline \multirow{2}{*}{ Aptitude } & \multicolumn{3}{|c|}{$\mathrm{R}\left(\widetilde{\mathrm{A}}_{\mathrm{i}}\right) ; \mathrm{i}=1,2,3}$. \\
\cline { 2 - 4 } & Young & Middle & Old \\
\hline Low & $\mathrm{A}_{1}(80.5015)$ & $\mathrm{A}_{2}(85.9993)$ & $\mathrm{A}_{3}(81.0011)$ \\
\hline Medium & $\mathrm{A}_{2}(91.001)$ & $\mathrm{A}_{3}(81.5011)$ & $\mathrm{A}_{1}(80.0011)$ \\
\hline High & $\mathrm{A}_{3}(88.5023)$ & $\mathrm{A}_{1}(83.501)$ & $\mathrm{A}_{2}(88.501)$ \\
\hline
\end{tabular}


The ANOVA table values of tfns. using Rezvani's Centroid Point:

Here, $\mathrm{Q}=134.9991 ; \mathrm{Q}_{1}=28.677, \mathrm{n}-1=2 ; \mathrm{Q}_{2}=21.5099, \mathrm{n}-1=2 ; \mathrm{Q}_{3}=80.1468, \mathrm{n}-1=2 ; \mathrm{Q}_{4}=4.6654$, $(\mathrm{n}-1)(\mathrm{n}-2)=2$ and variance ratio of $\mathrm{F}$ can be calculated as per the description of the ANOVA table noted in section-4. Now, $\mathrm{F}_{\text {Row }}=6.1467, \mathrm{~F}_{\mathrm{t}(5 \%)}(2,2)=19.00$. And $\mathrm{F}_{\text {Row }}<\mathrm{F}_{\mathrm{t}(5 \%)}$. $\Rightarrow$ The null hypothesis $\widetilde{\mathrm{H}}_{0}$ is accepted at $5 \%$ level of significance. $\Rightarrow$ The difference between rows is not significant. $\mathrm{F}_{\mathrm{Col} .}=4.6105, \quad \mathrm{~F}_{\mathrm{t}(5 \%)}(2,2)=19.00$. And $\mathrm{F}_{\mathrm{Col} .}<\mathrm{F}_{\mathrm{t}(5 \%)} . \Rightarrow$ The null hypothesis $\widetilde{\mathrm{H}}_{0}$ is accepted at $5 \%$ level of significance. $\Rightarrow$ The difference between columns is not significant. $\mathrm{F}_{\text {Treat. }}=17.1790, \mathrm{~F}_{\mathrm{t}(5 \%)}(2,2)=19.00$. And $\mathrm{F}_{\text {Treat. }}<\mathrm{F}_{\mathrm{t}(5 \%)} . \Rightarrow$ The null hypothesis $\widetilde{\mathrm{H}}_{0}$ is accepted at $5 \%$ level of significance. $\Rightarrow$ The difference between treatments is not significant. $\Rightarrow$ The difference among the three teaching methods is not significant.

\section{Graded mean integration representation (GMIR)}

Let $\widetilde{A}=(a, b, c, d ; w)$ be a generalized trapezoidal fuzzy number, then the GMIR [19] of $\widetilde{A}$ is defined by $P(\widetilde{A})=\int_{0}^{w} h\left[\frac{L^{-1}(h)+R^{-1}(h)}{2}\right] d h / \int_{0}^{w} h d h$.

Theorem 8.1. Let $\widetilde{A}=(a, b, c, d ; 1)$ be a tfn. with normal shape function, where a, b, c, d are real numbers such that $\mathrm{a}<\mathrm{b} \leq \mathrm{c}<\mathrm{d}$. Then the graded mean integration representation (GMIR) of $\widetilde{\mathrm{A}}$ is $P(\widetilde{A})=\frac{(a+d)}{2}+\frac{n}{2 n+1}(b-a-d+c)$.

Proof : For a trapezoidal fuzzy number $\widetilde{A}=(a, b, c, d ; 1)$, we have $L(x)=\left(\frac{x-a}{b-a}\right)^{n}$ and $\mathrm{R}(\mathrm{x})=\left(\frac{\mathrm{d}-\mathrm{x}}{\mathrm{d}-\mathrm{c}}\right)^{\mathrm{n}}$ Then, $\quad \mathrm{h}=\left(\frac{\mathrm{x}-\mathrm{a}}{\mathrm{b}-\mathrm{a}}\right)^{\mathrm{n}} \Rightarrow \mathrm{L}^{-1}(\mathrm{~h})=\mathrm{a}+(\mathrm{b}-\mathrm{a}) \mathrm{h}^{1 / \mathrm{n}}$

$\mathrm{h}=\left(\frac{\mathrm{d}-\mathrm{x}}{\mathrm{d}-\mathrm{c}}\right)^{\mathrm{n}} \Rightarrow \mathrm{R}^{-1}(\mathrm{~h})=\mathrm{d}-(\mathrm{d}-\mathrm{c}) \mathrm{h}^{1 / \mathrm{n}}$

$\therefore P(\widetilde{A})=\left(\frac{1}{2} \int_{0}^{1} h\left[\left(a+(b-a) h^{1 / n}\right)+\left(d-(d-c) h^{1 / n}\right)\right] d h\right) / \int_{0}^{1} h d h$

$$
=\left(\frac{1}{2}\left[\frac{(\mathrm{a}+\mathrm{d})}{2}+\frac{\mathrm{n}}{2 \mathrm{n}+1}(\mathrm{~b}-\mathrm{a}-\mathrm{d}+\mathrm{c})\right]\right) /(1 / 2)
$$

Thus, $P(\widetilde{A})=\frac{(a+d)}{2}+\frac{n}{2 n+1}(b-a-d+c)$ Hence the proof.

Result 8.1. If $\mathrm{n}=1$ in the above theorem, we have $P(\widetilde{A})=\frac{a+2 b+2 c+d}{6}$

Three-way ANOVA using GMIR of tfins.

Example 8.1. Let us consider example 1, using the result-8.1 from above theorem-8.1, we get the GMIR of each tfns. $\widetilde{\mathrm{A}}_{i}$ which are tabulated below:

\begin{tabular}{|c|c|c|c|}
\hline \multicolumn{4}{|c|}{$\mathrm{P}\left(\widetilde{\mathrm{A}}_{\mathrm{i}}\right) ; \mathrm{i}=1,2,3,4}$. \\
\hline $\mathrm{A}_{3}(24.1667)$ & $\mathrm{A}_{2}(22.5)$ & $\mathrm{A}_{1}(17.5)$ & $\mathrm{A}_{4}(19.5)$ \\
\hline $\mathrm{A}_{1}(18.5)$ & $\mathrm{A}_{4}(17)$ & $\mathrm{A}_{3}(21.8333)$ & $\mathrm{A}_{2}(17.5)$ \\
\hline $\mathrm{A}_{2}(19.5)$ & $\mathrm{A}_{1}(12.8333)$ & $\mathrm{A}_{4}(16.5)$ & $\mathrm{A}_{3}(20.6667)$ \\
\hline $\mathrm{A}_{4}(15.3333)$ & $\mathrm{A}_{3}(17.8333)$ & $\mathrm{A}_{2}(21.5)$ & $\mathrm{A}_{1}(13.6667)$ \\
\hline
\end{tabular}




\section{The ANOVA table values of tfns. using GMIR:}

Here, $Q=149.1048 ; \mathrm{Q}_{1}=36.62, \mathrm{n}-1=3 ; \mathrm{Q}_{2}=11.28, \mathrm{n}-1=3 ; \mathrm{Q}_{3}=80.90, \mathrm{n}-1=3 ; \mathrm{Q}_{4}=20.31$, $(n-1)(n-2)=6$ and variance ratio of $F$ can be calculated as per the description of the ANOVA table noted in section-4. Now, $\mathrm{F}_{\mathrm{Row}}=3.60, \mathrm{~F}_{\mathrm{t}(5 \%)}(3,6)=4.76$. And $\mathrm{F}_{\mathrm{Row}}<\mathrm{F}_{\mathrm{t}(5 \%)}$. $\Rightarrow$ The null hypothesis $\widetilde{\mathrm{H}}_{0}$ is accepted at $5 \%$ level of significance. $\Rightarrow$ The difference between rows is not significant. $\mathrm{F}_{\text {Col. }}=1.11, \mathrm{~F}_{\mathrm{t}(5 \%)}(3,6)=4.76$. And $\mathrm{F}_{\mathrm{Col}}<\mathrm{F}_{\mathrm{t}(5 \%)} . \Rightarrow$ The null hypothesis $\widetilde{\mathrm{H}}_{0}$ is accepted at $5 \%$ level of significance. $\Rightarrow$ The difference between columns is not significant. $\mathrm{F}_{\text {Treat. }}=7.96, \mathrm{~F}_{\mathrm{t}(5 \%)}(3,6)=4.76$. And $\mathrm{F}_{\text {Treat. }}>\mathrm{F}_{\mathrm{t}(5 \%)} . \Rightarrow$ The null hypothesis $\widetilde{\mathrm{H}}_{0}$ is rejected at $5 \%$ level of significance. $\Rightarrow$ The difference between treatments is significant. $\Rightarrow$ There is a significant difference among the methods of cultivation.

Example 8.2. Let us consider example 2, using the result-8.1 from above theorem-8.1, we get the GMIR of each tfns. $\widetilde{\mathrm{A}}_{i}$ which are tabulated below:

\begin{tabular}{|l|c|c|c|}
\hline \multirow{2}{*}{ Aptitude } & \multicolumn{3}{|c|}{$\mathrm{P}\left(\widetilde{\mathrm{A}}_{\mathrm{i}}\right) ; \mathrm{i}=1,2,3}$. \\
\cline { 2 - 4 } & Young & Middle & Old \\
\hline Low & $\mathrm{A}_{1}(80.6667)$ & $\mathrm{A}_{2}(85.6667)$ & $\mathrm{A}_{3}(81)$ \\
\hline Medium & $\mathrm{A}_{2}(91)$ & $\mathrm{A}_{3}(81.5)$ & $\mathrm{A}_{1}(80)$ \\
\hline High & $\mathrm{A}_{3}(89)$ & $\mathrm{A}_{1}(83.5)$ & $\mathrm{A}_{2}(88.5)$ \\
\hline
\end{tabular}

The ANOVA table values of tfns. using GMIR:

Here, $\quad \mathrm{Q}=137.0430 ; \mathrm{Q}_{1}=31.7466, \mathrm{n}-1=2 ; \quad \mathrm{Q}_{2}=25.1174, \quad \mathrm{n}-1=2 ; \quad \mathrm{Q}_{3}=75.7284, \quad \mathrm{n}-1=2$; $\mathrm{Q}_{4}=4.4506$, $(\mathrm{n}-1)(\mathrm{n}-2)=2$ and variance ratio of $\mathrm{F}$ can be calculated as per the description of the ANOVA table noted in section-4. Now, $\mathrm{F}_{\mathrm{Row}}=7.1331, \mathrm{~F}_{\mathrm{t}(5 \%)}(2,2)=19.00$. And $\mathrm{F}_{\mathrm{Row}}<\mathrm{F}_{\mathrm{t}(5 \%)} . \Rightarrow$

The null hypothesis $\widetilde{\mathrm{H}}_{0}$ is accepted at 5\% level of significance. $\Rightarrow$ The difference between rows is not significant. $\mathrm{F}_{\text {Col. }}=5.6436, \mathrm{~F}_{\mathrm{t}(5 \%)}(2,2)=19.00$. And $\mathrm{F}_{\mathrm{Col} .}<\mathrm{F}_{\mathrm{t}(5 \%)} . \Rightarrow$ The null hypothesis $\widetilde{\mathrm{H}}_{0}$ is accepted at $5 \%$ level of significance. $\Rightarrow$ The difference between columns is not significant. $\mathrm{F}_{\text {Treat. }}=17.0153, \mathrm{~F}_{\mathrm{t}(5 \%)}(2,2)=19.00$. And $\mathrm{F}_{\text {Treat. }}<\mathrm{F}_{\mathrm{t}(5 \%)} . \Rightarrow$ The null hypothesis $\widetilde{\mathrm{H}}_{0}$ is accepted at $5 \%$ level of significance. $\Rightarrow$ The difference between treatments is not significant. $\Rightarrow$ The difference among the three teaching methods is not significant.

\section{Three-way ANOVA model using membership function}

Proposition 9.1. (a) If $\widetilde{\mathrm{A}}=(\mathrm{a}, \mathrm{b}, \mathrm{c}, \mathrm{d}$; w $)$ is a generalized trapezoidal fuzzy number and ' $\mathrm{k}$ ' be a scalar with $\mathrm{k} \geq 0, \mathrm{y}=\mathrm{kA}$ then $\tilde{\mathrm{y}}=\mathrm{k} \widetilde{\mathrm{A}}$ is a fuzzy number with (ka, kb, kc, kd; w).(b)If $\widetilde{\mathrm{A}}=(\mathrm{a}, \mathrm{b}, \mathrm{c}, \mathrm{d} ; \mathrm{w})$ is a generalized trapezoidal fuzzy number and ' $\mathrm{k}$ ' be a scalar with $\mathrm{k}<0, \mathrm{y}=\mathrm{kA}$ then $\tilde{y}=k \widetilde{A}$ is a fuzzy number with $(k d, k c, k b, k a ; w)$.

Proof: (a) When $k \geq 0$, with the transformation $y=k A$ we can find the membership function of fuzzy set $\tilde{y}=k \widetilde{A}$ by $\alpha$-cut method. Now, the $\alpha$-cut interval of $\widetilde{A}$ is $\widetilde{\mathrm{A}}_{\alpha}=\left[\widetilde{\mathrm{A}}_{\mathrm{L}}(\alpha), \widetilde{\mathrm{A}}_{U}(\alpha)\right]$. That is $\widetilde{\mathrm{A}}_{\alpha}=\left[\mathrm{a}+\frac{\alpha}{\mathrm{W}}(\mathrm{b}-\mathrm{a}), \mathrm{d}-\frac{\alpha}{\mathrm{W}}(\mathrm{d}-\mathrm{c})\right]$. The lo $\alpha$-cut of $\widetilde{\mathrm{A}}$ is $\widetilde{\mathrm{A}}_{\mathrm{L}}(\alpha)=\mathrm{a}+\frac{\alpha}{\mathrm{w}}(\mathrm{b}-\mathrm{a})$ and the upper level $\alpha$-cut of $\widetilde{A}$ is $\widetilde{A}_{U}(\alpha)=d-\frac{\alpha}{w}(d-c)$. Hence, $A \in\left[a+\frac{\alpha}{w}(b-a), d-\frac{\alpha}{w}(d-c)\right]$. 
So, $y(=k A) \in\left[k a+\frac{\alpha}{w}(k b-k a), k d-\frac{\alpha}{w}(k d-k c)\right]$. So, $\frac{\alpha}{w}(k b-k a)=y-k a$.

$\Rightarrow \alpha=\mathrm{w}\left(\frac{\mathrm{y}-\mathrm{ka}}{\mathrm{kb}-\mathrm{ka}}\right) ; \mathrm{ka} \leq \mathrm{y} \leq \mathrm{kb}$

and $\frac{\alpha}{w}(\mathrm{kd}-\mathrm{kc})=\mathrm{kd}-\mathrm{y}$

$\Rightarrow \alpha=\mathrm{w}\left(\frac{\mathrm{y}-\mathrm{kd}}{\mathrm{kc}-\mathrm{kd}}\right) ; \mathrm{kc} \leq \mathrm{y} \leq \mathrm{kd}$

From (1) and (2), we have the membership function of $\tilde{y}=k \widetilde{A}$ as follows:

$\mu_{\tilde{y}}(y)=w\left(\frac{y-k a}{k b-k a}\right)$ for $k a \leq y \leq k b ; w$ for $k b \leq y \leq k c ; w\left(\frac{y-k d}{k c-k d}\right)$ for $k c \leq y \leq k d$;

and 0 , otherwise.

Similarly we can prove (b) if $\mathrm{y}=\mathrm{kA}, \mathrm{k}<0$ then $\tilde{\mathrm{y}}=(\mathrm{kd}, \mathrm{kc}, \mathrm{kb}, \mathrm{ka}$; w $)$ is a fuzzy number with membership function,

$\mu_{\tilde{y}}(y)=w\left(\frac{y-k d}{k c-k d}\right)$ for $k d \leq y \leq k c ; w$ for $k c \leq y \leq k b ; w\left(\frac{y-k a}{k b-k a}\right)$ for $k b \leq y \leq k a ;$

and 0 , otherwise.

And for a normalized trapezoidal number, we put $\mathrm{w}=1$ in equations (3) and (4).

Calculation of membership function of tfins.

The membership grades for a normalized tfn. $\tilde{y}=(a, b, c, d ; 1)$ is calculated by the relation [12]

$\int_{\operatorname{Supp}(\tilde{y})} \mu_{\tilde{y}}(y) d y=\int_{a}^{b}\left(\frac{y-a}{b-a}\right) d y+\int_{b}^{c} d y+\int_{c}^{d}\left(\frac{y-d}{c-d}\right) d y$

Example 9.1. Let us consider example 1, since for a normalized tfn. $\widetilde{A}, \mu_{\widetilde{A}}: X \rightarrow[0,1]$, we transform the tfns. in problem (1) by multiplying each members with " 0.01 " using proposition-9.1 and the membership grade of $1^{\text {st }}$ entry $\mathrm{A}_{3}(0.22,0.23,0.25,0.27 ; 1)$ will be

$\int_{\operatorname{Supp}\left(\widetilde{\mathrm{A}}_{\mathrm{i}}\right)} \mu_{\widetilde{\mathrm{A}}_{\mathrm{i}}}(\mathrm{y}) \mathrm{dy}=\int_{0.22}^{0.23}\left(\frac{\mathrm{y}-0.22}{0.01}\right) \mathrm{dy}+\int_{0.23}^{0.25} \mathrm{dy}+\int_{0.25}^{0.27}\left(\frac{\mathrm{y}-0.27}{-0.02}\right) \mathrm{dy}=0.035=\mathrm{I}$

Similarly we can calculate the membership grades of all other entries using $\int_{\operatorname{Supp}\left(\widetilde{A}_{i}\right)} \mu_{\widetilde{A}_{i}}(y) d y=I$ for the given tfns. which has been tabulated below.

\begin{tabular}{|c|c|c|c|}
\hline \multicolumn{4}{|c|}{$\int_{\operatorname{Supp}\left(\widetilde{\mathrm{A}}_{i}\right)} \mu_{\widetilde{\mathrm{A}}_{\mathrm{i}}}(\mathrm{y}) \mathrm{dy}=\mathrm{I}$} \\
\hline $\mathrm{A}_{3}(0.035)$ & $\mathrm{A}_{2}(0.03)$ & $\mathrm{A}_{1}(0.03)$ & $\mathrm{A}_{4}(0.03)$ \\
\hline $\mathrm{A}_{1}(0.03)$ & $\mathrm{A}_{4}(0.03)$ & $\mathrm{A}_{3}(0.035)$ & $\mathrm{A}_{2}(0.03)$ \\
\hline $\mathrm{A}_{2}(0.03)$ & $\mathrm{A}_{1}(0.035)$ & $\mathrm{A}_{4}(0.03)$ & $\mathrm{A}_{3}(0.035)$ \\
\hline $\mathrm{A}_{4}(0.025)$ & $\mathrm{A}_{3}(0.035)$ & $\mathrm{A}_{2}(0.03)$ & $\mathrm{A}_{1}(0.04)$ \\
\hline
\end{tabular}

The ANOVA table values of tfns. using membership grades:

Here, $\quad \mathrm{Q}=0.00019375 ; \mathrm{Q}_{1}=0.00000625, \mathrm{n}-1=3 ; \quad \mathrm{Q}_{2}=0.00003125, \mathrm{n}-1=3 ; \mathrm{Q}_{3}=0.00010625$, $\mathrm{n}-1=3 ; \mathrm{Q}_{4}=0.00005,(\mathrm{n}-1)(\mathrm{n}-2)=6$ and variance ratio of $\mathrm{F}$ can be calculated as per the description of the ANOVA table noted in section-4. Now, $\mathrm{F}_{\mathrm{Row}}=3.98, \mathrm{~F}_{\mathrm{t}(5 \%)}(6,3)=8.94$. And $\mathrm{F}_{\mathrm{Row}}<\mathrm{F}_{\mathrm{t}(5 \%)}$. $\Rightarrow$ The null hypothesis $\widetilde{H}_{0}$ is accepted at $5 \%$ level of significance. $\Rightarrow$ The difference between rows is 
not significant. $\mathrm{F}_{\text {Col. }}=1.26, \mathrm{~F}_{\mathrm{t}(5 \%)}(3,6)=4.76$. And $\mathrm{F}_{\mathrm{Col} .}<\mathrm{F}_{\mathrm{t}(5 \%)} . \Rightarrow$ The null hypothesis $\widetilde{\mathrm{H}}_{0}$ is accepted at $5 \%$ level of significance. $\Rightarrow$ The difference between columns is not significant. $\mathrm{F}_{\text {Treat. }}=4.27, \mathrm{~F}_{\mathrm{t}(5 \%)}(3,6)=4.76$. And $\mathrm{F}_{\text {Treat. }}<\mathrm{F}_{\mathrm{t}(5 \%)} . \Rightarrow$ The null hypothesis $\widetilde{\mathrm{H}}_{0}$ is accepted at $5 \%$ level of significance. $\Rightarrow$ The difference between treatments is not significant. $\Rightarrow$ The difference between the methods of cultivation is not significant.

Example 9.2. Let us consider example 2, since for a normalized tfn. $\widetilde{A}, \mu_{\widetilde{A}}: X \rightarrow[0,1]$, we transform the tfns. in problem (2) by multiplying each members with " 0.01 " using proposition-9.1 and the membership grade are tabulated below:

\begin{tabular}{|l|c|c|c|}
\hline \multirow{2}{*}{ Aptitude } & \multicolumn{3}{|c|}{$\int_{\operatorname{Supp}\left(\widetilde{\mathrm{A}}_{\mathrm{i}}\right)} \mu_{\widetilde{\mathrm{A}}_{\mathrm{i}}}(\mathrm{y}) \mathrm{dy}=\mathrm{I}$} \\
\cline { 2 - 4 } & Young & Middle & Old \\
\hline Low & $\mathrm{A}_{1}(0.055)$ & $\mathrm{A}_{2}(0.04)$ & $\mathrm{A}_{3}(0.05)$ \\
\hline Medium & $\mathrm{A}_{2}(0.05)$ & $\mathrm{A}_{3}(0.04)$ & $\mathrm{A}_{1}(0.05)$ \\
\hline High & $\mathrm{A}_{3}(0.055)$ & $\mathrm{A}_{1}(0.04)$ & $\mathrm{A}_{2}(0.04)$ \\
\hline
\end{tabular}

The ANOVA table values of tfns. using membership grades:

Here, $\quad \mathrm{Q}=0.00035 ; \mathrm{Q}_{1}=0.0000167, \mathrm{n}-1=2 ; \quad \mathrm{Q}_{2}=0.000267, \quad \mathrm{n}-1=2 ; \quad \mathrm{Q}_{3}=0.00005, \quad \mathrm{n}-1=2$; $\mathrm{Q}_{4}=0.0000167,(\mathrm{n}-1)(\mathrm{n}-2)=2$ and variance ratio of $\mathrm{F}$ can be calculated as per the description of the ANOVA table noted in section-4. Now, $\mathrm{F}_{\text {Row }}=1, \mathrm{~F}_{\mathrm{t}(5 \%)}(2,2)=19.00$. And $\mathrm{F}_{\text {Row }}<\mathrm{F}_{\mathrm{t}(5 \%)}$. $\Rightarrow$ The null hypothesis $\widetilde{\mathrm{H}}_{0}$ is accepted at $5 \%$ level of significance. $\Rightarrow$ The difference between rows is not significant. $\mathrm{F}_{\text {Col. }}=15.99, \mathrm{~F}_{\mathrm{t}(5 \%)}(2,2)=19.00$. And $\mathrm{F}_{\mathrm{Col} .}<\mathrm{F}_{\mathrm{t}(5 \%)} \Rightarrow$ The null hypothesis $\widetilde{\mathrm{H}}_{0}$ is accepted at $5 \%$ level of significance. $\Rightarrow$ The difference between columns is not significant. $\mathrm{F}_{\text {Treat. }}=2.99$, $\mathrm{F}_{\mathrm{t}(5 \%)}(2,2)=19.00$. And $\mathrm{F}_{\text {Treat. }}<\mathrm{F}_{\mathrm{t}(5 \%)} . \Rightarrow$ The null hypothesis $\widetilde{\mathrm{H}}_{0}$ is accepted at $5 \%$ level of significance. $\Rightarrow$ The difference between treatments is not significant. $\Rightarrow$ The difference among the three teaching methods is not significant.

\section{LIOU and WANG'S centroid point method}

Liou and Wang [14] ranked fuzzy numbers with total integral value. For a fuzzy number defined by definition (2.3), the total integral value is defined as

$$
\begin{aligned}
& I_{T}^{\alpha}(\widetilde{A})=\alpha I_{R}(\widetilde{A})+(1-\alpha) I_{L}(\widetilde{A}) \\
& \text { where } I_{R}(\widetilde{A})=\int_{\operatorname{Supp}(\widetilde{A})} R_{\widetilde{A}}(x) d x=\int_{c}^{d}\left(\frac{x-d}{c-d}\right) d x \\
& I_{L}(\widetilde{A})=\int_{\operatorname{Supp}(\widetilde{A})} L_{\widetilde{A}}(x) d x=\int_{a}^{b}\left(\frac{x-a}{b-a}\right) d x
\end{aligned}
$$

are the right and left integral values of $\widetilde{\mathrm{A}}$ respectively and $0 \leq \alpha \leq 1$.

(i) $\alpha \in[0,1]$ is the index of optimism which represents the degree of optimism of a decision maker.

(ii) If $\alpha=0$, then the total value of integral represents a pessimistic decision maker's view point which is equal to left integral value. (iii) If $\alpha=1$, then the total integral value represents an optimistic decision maker's view point and is equal to the right integral value.(iv)If $\alpha=0.5$ then the total integral value represents a moderate decision maker's view point and is equal to the mean of right and left integral values. For a decision maker, the larger the value of $\alpha$ is, the higher is the degree of optimism. 
The ANOVA test using LIOU and WANG'S centroid point method:

Example 10.1. Let us consider example 1, using the above equations (10.1), (10.2) and (10.3), we get the centroid point of first member as follows:

$I_{L}\left(\widetilde{A}_{3}\right)=\int_{22}^{23}(x-22) d x=1 / 2 ; \quad I_{R}\left(\widetilde{A}_{3}\right)=\int_{25}^{27}\left(\frac{x-27}{-2}\right) d x=1$ Therefore $I_{T}^{\alpha}\left(\widetilde{A}_{3}\right)=(1+\alpha) / 2$.

Similarly we can find $\mathrm{I}_{\mathrm{T}}^{\alpha}\left(\widetilde{\mathrm{A}}_{\mathrm{i}}\right)$; for $\mathrm{i}=1,2,3,4$. and the calculated values are tabulated below:

\begin{tabular}{|c|c|c|c|}
\hline \multicolumn{4}{|c|}{$\mathrm{I}_{\mathrm{T}}^{\alpha}\left(\widetilde{\mathrm{A}}_{\mathrm{i}}\right) ; \mathrm{i}=1,2,3,4}$. \\
\hline $\mathrm{A}_{3}(1+\alpha) / 2$ & $\mathrm{~A}_{2}(1)$ & $\mathrm{A}_{1}(1)$ & $\mathrm{A}_{4}(1)$ \\
\hline $\mathrm{A}_{1}(1)$ & $\mathrm{A}_{4}(1 / 2)$ & $\mathrm{A}_{3}(2-\alpha) / 2$ & $\mathrm{~A}_{2}(1)$ \\
\hline $\mathrm{A}_{2}(1)$ & $\mathrm{A}_{1}(2-\alpha) / 2$ & $\mathrm{~A}_{4}(1)$ & $\mathrm{A}_{3}(2+\alpha) / 2$ \\
\hline $\mathrm{A}_{4}(2-\alpha) / 2$ & $\mathrm{~A}_{3}(2-\alpha) / 2$ & $\mathrm{~A}_{2}(1)$ & $\mathrm{A}_{1}(3-2 \alpha) / 2$ \\
\hline
\end{tabular}

The ANOVA table values of tfns. using LIOU and WANG'S centroid point method:

Here, $\quad \mathrm{Q}=\left(144 \alpha^{2}-104 \alpha+47\right) / 64 ; \mathrm{Q}_{1}=\left(56 \alpha^{2}-40 \alpha+11\right) / 64, \mathrm{n}-1=3 ; \mathrm{Q}_{2}=\left(8 \alpha^{2}+11\right) / 64, \quad \mathrm{n}-1=3$; $\mathrm{Q}_{3}=\left(24 \alpha^{2}-24 \alpha+11\right) / 64, \mathrm{n}-1=3 ; \mathrm{Q}_{4}=\left(28 \alpha^{2}-20 \alpha+7\right) / 32,(\mathrm{n}-1)(\mathrm{n}-2)=6$ and variance ratio of $\mathrm{F}$ can be calculated as per the description of the ANOVA table noted in section-4. Now, $\mathrm{F}_{\text {Row }}=\frac{56 \alpha^{2}-40 \alpha+11}{28 \alpha^{2}-20 \alpha+7} ; 0 \leq \alpha \leq 1, \quad \mathrm{~F}_{\mathrm{t}(5 \%)}(3,6)=4.76$. And $\quad \mathrm{F}_{\text {Row }}<\mathrm{F}_{\mathrm{t}(5 \%)} \forall \alpha, \alpha \in[0,1] . \Rightarrow$ The null hypothesis $\widetilde{\mathrm{H}}_{0}$ is accepted at $5 \%$ level of significance. $\Rightarrow$ The difference between rows is not significant. $\quad \mathrm{F}_{\mathrm{Col} .}=\frac{8 \alpha^{2}+11}{28 \alpha^{2}-20 \alpha+7} ; 0 \leq \alpha \leq 1, \quad \mathrm{~F}_{\mathrm{t}(5 \%)}(3,6)=4.76 . \quad \operatorname{AndF}_{\mathrm{Col} .}<\mathrm{F}_{\mathrm{t}(5 \%)} \forall \alpha, \alpha \in[0,1] . \Rightarrow$ The null hypothesis $\widetilde{\mathrm{H}}_{0}$ is accepted at $5 \%$ level of significance. $\Rightarrow$ The difference between columns is not significant. $\mathrm{F}_{\text {Treat. }}=\frac{24 \alpha^{2}-24 \alpha+11}{28 \alpha^{2}-20 \alpha+7} ; 0 \leq \alpha \leq 1, \mathrm{~F}_{\mathrm{t}(5 \%)}(3,6)=4.76$. And $_{\text {Treat. }}<\mathrm{F}_{\mathrm{t}(5 \%)} \forall \alpha, \alpha \in[0,1] . \Rightarrow$ The null hypothesis $\widetilde{\mathrm{H}}_{0}$ is accepted at $5 \%$ level of significance. $\Rightarrow$ The difference between treatments is not significant. $\Rightarrow$ The difference between the methods of cultivation is not significant.

Example 10.2. Let us consider example 2, using the above equations (10.1), (10.2) and (10.3), we get the centroid points of tfns. as follows:

\begin{tabular}{|l|c|c|c|}
\hline \multirow{2}{*}{ Aptitude } & \multicolumn{3}{|c|}{$\mathrm{I}_{\mathrm{T}}^{\alpha}\left(\widetilde{\mathrm{A}}_{\mathrm{i}}\right) ; \mathrm{i}=1,2,3}$. \\
\cline { 2 - 4 } & Young & Middle & Old \\
\hline Low & $\mathrm{A}_{1}(2+\alpha) / 2$ & $\mathrm{~A}_{2}(3-4 \alpha) / 2$ & $\mathrm{~A}_{3}(3 / 2)$ \\
\hline Medium & $\mathrm{A}_{2}(3 / 2)$ & $\mathrm{A}_{3}(3 / 2)$ & $\mathrm{A}_{1}(3 / 2)$ \\
\hline High & $\mathrm{A}_{3}(1+3 \alpha) / 2$ & $\mathrm{~A}_{1}(3 / 2)$ & $\mathrm{A}_{2}(3 / 2)$ \\
\hline
\end{tabular}

The ANOVA table values of tfns. using LIOU and WANG'S centroid point method:

Here, $\quad \mathrm{Q}=\left(13 \alpha^{2}-7 \alpha+2\right) / 2 ; \mathrm{Q}_{1}=\left(9 \alpha^{2}-3 \alpha+1\right) / 6, \mathrm{n}-1=2 ; \quad \mathrm{Q}_{2}=\left(16 \alpha^{2}-12 \alpha+3\right) / 6, \quad \mathrm{n}-1=2$; $\mathrm{Q}_{3}=\left(13 \alpha^{2}-7 \alpha+1\right) / 6, \quad \mathrm{n}-1=2 ; \mathrm{Q}_{4}=\left(\alpha^{2}+\alpha+1\right) / 6,(\mathrm{n}-1)(\mathrm{n}-2)=2$ and variance ratio of $\mathrm{F}$ can be calculated as per the description of the ANOVA table noted in section-4. Now, $\mathrm{F}_{\text {Row }}=\frac{9 \alpha^{2}-3 \alpha+1}{\alpha^{2}+\alpha+1} ; 0 \leq \alpha \leq 1, \quad \mathrm{~F}_{\mathrm{t}(5 \%)}(2,2)=19.00 . \quad$ And $\quad \mathrm{F}_{\text {Row }}<\mathrm{F}_{\mathrm{t}(5 \%)}, \forall \alpha, \alpha \in[0,1] . \Rightarrow$ The $\quad$ null hypothesis $\widetilde{\mathrm{H}}_{0}$ is accepted at $5 \%$ level of significance. $\Rightarrow$ The difference between rows is not significant. $\mathrm{F}_{\mathrm{Col} .}=\frac{16 \alpha^{2}-12 \alpha+3}{\alpha^{2}+\alpha+1} ; 0 \leq \alpha \leq 1, \mathrm{~F}_{\mathrm{t}(5 \%)}(2,2)=19.00 . \quad$ And $\mathrm{F}_{\mathrm{Col} .}<\mathrm{F}_{\mathrm{t}(5 \%)}, \forall \alpha, \alpha \in[0,1] . \Rightarrow$ The 
null hypothesis $\widetilde{\mathrm{H}}_{0}$ is accepted at $5 \%$ level of significance. $\Rightarrow$ The difference between columns is not significant. $\quad \mathrm{F}_{\text {Treat. }}=\frac{13 \alpha^{2}-7 \alpha+1}{\alpha^{2}+\alpha+1} ; 0 \leq \alpha \leq 1, \quad \mathrm{~F}_{\mathrm{t}(5 \%)}(2,2)=19.00 . \quad \operatorname{AndF}_{\text {Treat. }}<\mathrm{F}_{\mathrm{t}(5 \%)}, \forall \alpha, \alpha \in[0,1] . \Rightarrow$ The null hypothesis $\widetilde{\mathrm{H}}_{0}$ is accepted at $5 \%$ level of significance. $\Rightarrow$ The difference between treatments is not significant. $\Rightarrow$ The difference among the three teaching methods is not significant.

\section{Thorani's ranking method}

As per the description in Salim Rezvani's ranking method, Thorani et al. [21] presented a different kind of centroid point and ranking function of tfns. The incenter $\mathrm{I}_{\widetilde{\mathrm{A}}}\left(\overline{\mathrm{x}}_{0}, \overline{\mathrm{y}}_{0}\right)$ of the triangle [Fig. 1] with vertices $G_{1}, G_{2}$ and $G_{3}$ of the generalized tfn. $\widetilde{A}=(a, b, c, d ; w)$ is given by,

$$
\begin{gathered}
\mathrm{I}_{\widetilde{\mathrm{A}}}\left(\overline{\mathrm{x}}_{0}, \overline{\mathrm{y}}_{0}\right)=\left[\frac{\alpha\left(\frac{\mathrm{a}+2 \mathrm{~b}}{3}\right)+\beta\left(\frac{\mathrm{b}+\mathrm{c}}{2}\right)+\gamma\left(\frac{2 \mathrm{c}+\mathrm{d}}{3}\right)}{\alpha+\beta+\gamma}, \frac{\alpha\left(\frac{\mathrm{w}}{3}\right)+\beta\left(\frac{\mathrm{w}}{2}\right)+\gamma\left(\frac{\mathrm{w}}{3}\right)}{\alpha+\beta+\gamma}\right] \\
\text { where } \alpha=\frac{\sqrt{(\mathrm{c}-3 \mathrm{~b}+2 \mathrm{~d})^{2}+\mathrm{w}^{2}}}{6}, \beta=\frac{\sqrt{(2 \mathrm{c}+\mathrm{d}-\mathrm{a}-2 \mathrm{~b})^{2}}}{3}, \gamma=\frac{\sqrt{(3 \mathrm{c}-2 \mathrm{a}-\mathrm{b})^{2}+\mathrm{w}^{2}}}{6}
\end{gathered}
$$

And the ranking function of the generalized TFN $\widetilde{A}=(a, b, c, d ; w)$ which maps the set of all fuzzy numbers to a set of real numbers is defined as $\mathrm{R}(\widetilde{\mathrm{A}})=\mathrm{x}_{0} \times \mathrm{y}_{0}$

For a normalized TFN, we put $\mathrm{w}=1$ in equations (1) and (2) so we have,

$$
\begin{aligned}
& \mathrm{I}_{\widetilde{\mathrm{A}}}\left(\overline{\mathrm{x}}_{0}, \overline{\mathrm{y}}_{0}\right)=\left[\frac{\alpha\left(\frac{\mathrm{a}+2 \mathrm{~b}}{3}\right)+\beta\left(\frac{\mathrm{b}+\mathrm{c}}{2}\right)+\gamma\left(\frac{2 \mathrm{c}+\mathrm{d}}{3}\right)}{\alpha+\beta+\gamma}, \frac{\alpha\left(\frac{1}{3}\right)+\beta\left(\frac{1}{2}\right)+\gamma\left(\frac{1}{3}\right)}{\alpha+\beta+\gamma}\right] \\
& \text { where } \alpha=\frac{\sqrt{(\mathrm{c}-3 \mathrm{~b}+2 \mathrm{~d})^{2}+1}}{6}, \beta=\frac{\sqrt{(2 \mathrm{c}+\mathrm{d}-\mathrm{a}-2 \mathrm{~b})^{2}}}{3} \text { and } \gamma=\frac{\sqrt{(3 \mathrm{c}-2 \mathrm{a}-\mathrm{b})^{2}+1}}{6}
\end{aligned}
$$

And for $\widetilde{A}=(a, b, c, d ; 1), \quad R(\widetilde{A})=x_{0} \times y_{0}$

Thorani's ranking method for three-way ANOVA test

Example 11.1. Let us consider example 1, using the above relations (11.3) and (11.4), we get the ranks of each tfns. $\widetilde{\mathrm{A}}_{i}$ which are tabulated below:

\begin{tabular}{|c|c|c|c|}
\hline \multicolumn{4}{|c|}{$\mathrm{R}\left(\widetilde{\mathrm{A}}_{\mathrm{i}}\right) ; \mathrm{i}=1,2,3,4}$. \\
\hline $\mathrm{A}_{3}(9.99422)$ & $\mathrm{A}_{2}(9.36553)$ & $\mathrm{A}_{1}(7.2843)$ & $\mathrm{A}_{4}(8.11679)$ \\
\hline $\mathrm{A}_{1}(7.70055)$ & $\mathrm{A}_{4}(7.07784)$ & $\mathrm{A}_{3}(9.16054)$ & $\mathrm{A}_{2}(7.2843)$ \\
\hline $\mathrm{A}_{2}(8.11679)$ & $\mathrm{A}_{1}(5.41287)$ & $\mathrm{A}_{4}(6.86806)$ & $\mathrm{A}_{3}(8.53549)$ \\
\hline $\mathrm{A}_{4}(6.44827)$ & $\mathrm{A}_{3}(7.49491)$ & $\mathrm{A}_{2}(8.94928)$ & $\mathrm{A}_{1}(5.8296)$ \\
\hline
\end{tabular}

The ANOVA table values of tfns. using Thorani's ranking method:

Here, $Q=24.53 ; \mathrm{Q}_{1}=5.91, \mathrm{n}-1=3 ; \mathrm{Q}_{2}=1.85, \mathrm{n}-1=3 ; \mathrm{Q}_{3}=13.46, \mathrm{n}-1=3 ; \mathrm{Q}_{4}=3.32,(\mathrm{n}-1)(\mathrm{n}-2)=6$ and variance ratio of $\mathrm{F}$ can be calculated as per the description of the ANOVA table noted in section- 4 . Now, $\mathrm{F}_{\text {Row }}=3.58, \mathrm{~F}_{\mathrm{t}(5 \%)}(3,6)=4.76$. And $\mathrm{F}_{\text {Row }}<\mathrm{F}_{\mathrm{t}(5 \%)} . \Rightarrow$ The null hypothesis $\widetilde{\mathrm{H}}_{0}$ is accepted at $5 \%$ level of significance. $\Rightarrow$ The difference between rows is not significant. $\mathrm{F}_{\text {Col. }}=1.13, \mathrm{~F}_{\mathrm{t}(5 \%)}(3,6)=4.76$. And $\mathrm{F}_{\mathrm{Col} .}<\mathrm{F}_{\mathrm{t}(5 \%)} . \Rightarrow$ The null hypothesis $\widetilde{\mathrm{H}}_{0}$ is accepted at $5 \%$ level of significance. $\Rightarrow$ The difference 
between columns is not significant. $\mathrm{F}_{\text {Treat. }}=8.16, \mathrm{~F}_{\mathrm{t}(5 \%)}(3,6)=4.76$. And $\mathrm{F}_{\text {Treat. }}>\mathrm{F}_{\mathrm{t}(5 \%)} \Rightarrow$ The null hypothesis $\widetilde{\mathrm{H}}_{0}$ is rejected at $5 \%$ level of significance. $\Rightarrow$ The difference between treatments is significant. $\Rightarrow$ The difference between the methods of cultivation is significant.

Example 11.2. Let us consider example 2, using the above relations (11.3) and (11.4), we get the ranks of each tfns. $\widetilde{\mathrm{A}}_{i}$ which are tabulated below:

\begin{tabular}{|l|c|c|c|}
\hline \multirow{2}{*}{ Aptitude } & \multicolumn{3}{|c|}{$\mathrm{R}\left(\widetilde{\mathrm{A}}_{\mathrm{i}}\right) ; \mathrm{i}=1,2,3}$. \\
\cline { 2 - 4 } & Young & Middle & Old \\
\hline Low & $\mathrm{A}_{1}(33.533)$ & $\mathrm{A}_{2}(35.8141)$ & $\mathrm{A}_{3}(33.7383)$ \\
\hline Medium & $\mathrm{A}_{2}(37.9035)$ & $\mathrm{A}_{3}(33.9375)$ & $\mathrm{A}_{1}(33.3218)$ \\
\hline High & $\mathrm{A}_{3}(36.8657)$ & $\mathrm{A}_{1}(34.7703)$ & $\mathrm{A}_{2}(36.8524)$ \\
\hline
\end{tabular}

The ANOVA table values of tfns. using Thorani's ranking method:

Here, $\mathrm{Q}=23.4122 ; \mathrm{Q}_{1}=4.9520, \mathrm{n}-1=2 ; \mathrm{Q}_{2}=3.7702, \mathrm{n}-1=2 ; \mathrm{Q}_{3}=13.8733, \mathrm{n}-1=2 ; \mathrm{Q}_{4}=0.8168$, $(n-1)(n-2)=2$ and variance ratio of $F$ can be calculated as per the description of the ANOVA table noted in section-4. Now, $\mathrm{F}_{\text {Row }}=6.0627, \mathrm{~F}_{\mathrm{t}(5 \%)}(2,2)=19.00$. And $\mathrm{F}_{\text {Row }}<\mathrm{F}_{\mathrm{t}(5 \%)}$. $\Rightarrow$ The null hypothesis $\widetilde{\mathrm{H}}_{0}$ is accepted at $5 \%$ level of significance. $\Rightarrow$ The difference between rows is not significant. $\mathrm{F}_{\text {Col. }}=4.6158, \mathrm{~F}_{\mathrm{t}(5 \%)}(2,2)=19.00$. And $\mathrm{F}_{\mathrm{Col} .}<\mathrm{F}_{\mathrm{t}(5 \%)} . \Rightarrow$ The null hypothesis $\widetilde{\mathrm{H}}_{0}$ is accepted at $5 \%$ level of significance. $\Rightarrow$ The difference between columns is not significant. $\mathrm{F}_{\text {Treat. }}=16.9851$, $\mathrm{F}_{\mathrm{t}(5 \%)}(2,2)=19.00$. And $\mathrm{F}_{\text {Treat. }}<\mathrm{F}_{\mathrm{t}(5 \%)} . \Rightarrow$ The null hypothesis $\widetilde{\mathrm{H}}_{0}$ is accepted at $5 \%$ level of significance. $\Rightarrow$ The difference between treatments is not significant. $\Rightarrow$ The difference among the three teaching methods is not significant.

\section{Conclusion:}

The decisions obtained from various methods are tabulated below for the null hypothesis.

\begin{tabular}{|c|c|c|c|c|c|c|c|c|c|c|c|c|c|c|c|c|}
\hline \multirow{4}{*}{ S.V. } & \multicolumn{16}{|c|}{ Acceptance of null hypotheses $\widetilde{\mathrm{H}}_{0}$} \\
\hline & \multicolumn{4}{|c|}{$\alpha$ cut method } & \multicolumn{2}{|c|}{ Wang } & \multicolumn{2}{|c|}{ Rezvani } & \multicolumn{2}{|c|}{ GMIR } & \multicolumn{2}{|c|}{ M.F. } & \multicolumn{2}{|c|}{$\mathbf{L} \& \mathbf{W}$} & \multicolumn{2}{|c|}{ Thorani } \\
\hline & & & Eg & & & $\mathrm{Fo} 2$ & & & & & & & & & Eg. & Eg. \\
\hline & $\mathrm{L}$ & $\mathrm{U}$ & $\mathrm{L}$ & $\mathrm{U}$ & Eg.1 & Eg.2 & Eg.1 & Eg.2 & Eg.1 & Eg.2 & Eg. 1 & Eg.2 & Eg.1 & Eg.2 & 1 & 2 \\
\hline Between Rows & $\checkmark$ & $\checkmark$ & $\checkmark$ & $\checkmark$ & $\checkmark$ & $\checkmark$ & $\checkmark$ & $\checkmark$ & $\checkmark$ & $\checkmark$ & $\checkmark$ & $\checkmark$ & $\checkmark$ & $\checkmark$ & $\checkmark$ & $\checkmark$ \\
\hline Between Columns & $\checkmark$ & $\checkmark$ & $\checkmark$ & $\checkmark$ & $\checkmark$ & $\checkmark$ & $\checkmark$ & $\checkmark$ & $\checkmark$ & $\checkmark$ & $\checkmark$ & $\checkmark$ & $\checkmark$ & $\checkmark$ & $\checkmark$ & $\checkmark$ \\
\hline Between Treat. & $x$ & $x$ & $x$ & $\checkmark$ & $x$ & $\checkmark$ & $x$ & $\checkmark$ & $x$ & $\checkmark$ & $\checkmark$ & $\checkmark$ & $\checkmark$ & $\checkmark$ & $x$ & $\checkmark$ \\
\hline
\end{tabular}

Observing the decisions obtained from $\alpha$-cut interval method, for example-1, the difference between rows and columns is not significant and there is a significant difference between treatments. For example-2, the difference between rows and columns is not significant and there is a significant difference between treatments. Moreover, the membership function and Liou \& Wang's method $(\mathrm{L} \& \mathrm{~W})$ do not provide reliable results as they accept the null hypotheses for all cases. Also, decisions from ranking grades of Wang, Rezvani, Thorani and GMIR provide parallel discussions.

\section{References}

[1] S. Abbasbandy, B. Asady, The nearest trapezoidal fuzzy number to a fuzzy quantity, Appl. Math. Comput., 156 (2004) 381-386.

[2] S. Abbasbandy, M. Amirfakhrian, The nearest approximation of a fuzzy quantity in parametric form, Appl. Math. Comput., 172 (2006) 624-632.

[3] S. Abbasbandy, M. Amirfakhrian, The nearest trapezoidal form of generalized left right fuzzy number, Internat. J. Approx. Reason., 43 (2006) 166-178.

[4] S. Abbasbandy, T. Hajjari, Weighted trapezoidal approximation-preserving cores of a fuzzy number, Computers and Mathematics with Applications, 59 (2010) 3066-3077. 
[5] E. Baloui Jamkhaneh and A. Nadi Ghara, Testing statistical hypotheses for compare means with vague data, International Mathematical Forum, 5 (2010) 615-620.

[6] S. Bodjanova, Median value and median interval of a fuzzy number, Inform. Sci. 172 (2005) 73-89.

[7] J. J. Buckley, Fuzzy statistics, Springer-Verlag, New York, 2005.

[8] J. Chachi, S. M. Taheri and R. Viertl, Testing statistical hypotheses based on fuzzy confidence intervals, Forschungsbericht SM-2012-2, Technische Universitat Wien, Austria, 2012.

[9] D. Dubois and H. Prade, Operations on fuzzy numbers, Int. J. Syst. Sci., 9 (1978) 613-626.

[10] S. C. Gupta, V. K. Kapoor, Fundamentals of mathematical statistics, Sultan Chand \& Sons, New Delhi, India.

[11]R. R. Hocking, Methods and applications of linear models: regression and the analysis of variance, New York: John Wiley \& Sons, 1996.

[12] Iuliana Carmen BĂRBĂCIORU, Statistical Hypothesis Testing Using Fuzzy Linguistic Variables, Fiabilitatesi Durabilitate-Fiability \& Durability, Supplement, 1 (2012) Editura "Academica Brâncusi", Târgu Jiu, ISSN 1844-640X.

[13] George J. Klir and Bo Yuan, Fuzzy sets and fuzzy logic, Theory and Applications, PrenticeHall, New Jersey, 2008.

[14]T. S. Liou and M. J. Wang, Ranking Fuzzy Numbers with Integral Value, Fuzzy Sets and Systems, 50 (1992) 247-225.

[15] Mikihiko Konishi, Tetsuji Okuda and Kiyoji Asai, Analysis of variance based on Fuzzy interval data using moment correction method, International Journal of Innovative Computing, Information and Control, 2 (2006) 83-99.

[16] S. Parthiban, and P. Gajivaradhan, One-factor ANOVA model using trapezoidal fuzzy numbers through alpha cut interval method, Annals of Pure and Applied Mathematics, 11(1) (2016) 4561.

[17] S. Parthiban, and P. Gajivaradhan, A comparative study of two factor ANOVA model under fuzzy environments using trapezoidal fuzzy numbers, Int. J. of Fuzzy Mathematical Archive, 10(1) (2016) 1-25.

[18] S. Salahsour, S. Abbasbandy and T. Allahviranloo, Ranking Fuzzy Numbers using Fuzzy Maximizing-Minimizing points, EUSFLAT-LFA: July 2011, Aix-les-Bains, France.

[19] Salim Rezvani and Mohammad Molani, Representation of trapezoidal fuzzy numbers with shape function, to appear in Annals of Fuzzy mathematics and Informatics.

[20] Salim Rezvani, Ranking Generalized Trapezoidal Fuzzy Numbers with Euclidean Distance by the Incentre of Centroids, Mathematica Aeterna, 3 (2) (2013) 103-114.

[21] Y. L. P. Thorani, et al., Ordering Generalized Trapezoidal Fuzzy Numbers, Int. J. Contemp. Math. Sciences, 7(12) (2012) 555-573.

[22] T. Veerarajan, Probability, statistics and random process, Tata McGraw Hill Education Pvt. Ltd., New Delhi, India.

[23] R. Viertl, Statistical methods for fuzzy data, John Wiley and Sons, Chichester, 2011.

[24]R. Viertl, Univariate statistical analysis with fuzzy data, Computational Statistics and Data Analysis, 51 (2006) 33-147.

[25]Y. M. Wang et al., On the centroids of fuzzy numbers, Fuzzy Sets and Systems, 157 (2006) 919-926.

[26] H. C. Wu, Analysis of variance for fuzzy data, International Journal of Systems Science, 38 (2007) 235-246.

[27]H. C. Wu, Statistical confidence intervals for fuzzy data, Expert Systems with Applications, 36 (2009) 2670-2676.

[28]H. C. Wu, Statistical hypotheses testing for fuzzy data, Information Sciences, 175 (2005) 3056.

[29]L. A. Zadeh, Fuzzy sets, Information and Control, 8 (1965) 338-353. 